\title{
Analysis of Fatigue Strain, Fatigue Modulus and Fatigue Damage for the Model formulation of Concrete based on Strain Life Approach
}

\author{
Indra Narayan Yadav ${ }^{1}$, Dr. Kamal Bahadur Thapa ${ }^{2}$ \\ ${ }^{1}$ Ph.D. Research Scholar, Department of Civil Engineering, Pulchowk Campus, Institute of \\ Engineering, Tribhuvan University, Nepal \\ ${ }^{2}$ Associate Professor, Department of Civil Engineering, Pulchowk Campus, Institute of Engineering, \\ Tribhuvan University, Nepal
}

Corresponding emails: ${ }^{1}$ eecconsultant@gmail.com, ${ }^{2}$ kamal.thapa@ioe.edu.np

\begin{abstract}
Analysis of Fatigue Strain, Fatigue Modulus and Fatigue Damage for the modeling of concrete plays a vital role in the evolution material behaviour which is heterogeneous and anisotropic in nature. In this paper, the Level-S nonlinear fatigue strain curve, fatigue modulus curve, residual strain curve of concrete in compression, tension, flexure and torsional fatigue loading were proposed using strain life approach. The parameters such as physical meaning, the ranges, and the impact on the shape of the curve were discussed. Then, the evolution model of fatigue modulus was established based on the fatigue strain evolution model, fatigue modulus evaluation model, residual strain evaluation model, secondary strain evaluation model. The hypothesis of fatigue modulus is inversely related with the fatigue strain amplitude. The fatigue evolution of concrete damages the bond between material grains, changed the orientation of structure of molecules and affects the elastic properties resulting in the reduction of material stiffness and modulus by utilizing strain life analysis, regarding stiffness degradation and inelastic deformation by formation of microcracking, macro cracking, cracking which is heterogeneous and anisotropic in nature. This paper presents the Fatigue Strain Life Model and analyses of fatigue strain, fatigue modulus and damage parameters of concrete which is capable of predicting stiffness degradation, inelastic deformation, strength reduction under fatigue loading. Hence, the obtainable results were compared with experimental results for the validation of the proposed model.
\end{abstract}

Keywords: Fatigue Strain Life Approach; Fatigue Strain evolution Model; Fatigue Modulus evolution Model; Fatigue residual strain evolution Model; Fatigue Secondary Strain; Stiffness. 


\section{Introduction}

In recent years, concrete has been widely used in every civil engineering works directly or indirectly which includes: construction of residential houses, industrial warehouses, road pavements construction, shore protection works, piles, domes, bridges, culverts, drainages, canals, dams etc. (Shetty, 2005; Neville, 2011; Edward and David, 2009; Duggal, 2009; Gambhir, 2005). In most civil engineering works, the cases of failure of structures and roads (concrete related failures) occur every year.

The fatigue loading of a concrete element is well-known progressive deterioration of concrete. Once cracks develops in the concrete, the reinforcement crack propagation at the intersection of the cracked concrete planes may occur depending on the magnitude of the induced stress in the steel reinforcement. However, robust models required for the prediction of the fatigue life of these elements are not readily available. This is attributed to the complex degradation mechanisms for steel and concrete composites inherent in any fatigue damage process (Isojeh et al., 2017). To fully account for fatigue damage mechanisms, concrete integrity deterioration, irreversible strain accumulation, and reinforcement crack growth should be considered. Herein, the mechanism is incorporated into the constitutive, compatibility and equilibrium equations of the Disturbed Stress Field Model (DSFM) (Vecchio, 2000) analysis algorithm to predict the fatigue residual capacity of the structural element. The fatigue life of the structural element corresponds to the instance when the fatigue residual capacity becomes equal to the applied fatigue load (Isojeh et al., 2017).

Concrete fatigue strain can be a true reflection of the variation of material deformation under fatigue loading. If the relationship between the curve and the cycles is known, a qualitative and quantitative description of the material fatigue strain evolution can be provided, hence providing the basis for the evaluation of material behavior. Most of the amplitude fatigue test showed that, whether ordinary concrete, lightweight aggregate concrete, high strength concrete, or fiber reinforced concrete, and whether compression fatigue, tension fatigue, bending fatigue, uniaxial fatigue, or multi-axial fatigue, the longitudinal total deformation and the residual deformation of the concrete exhibit a very stable three-stage development law.

Under fatigue loads, the rate of change of deformation is truly illustrated by the fatigue strain. By understanding the nature and behaviour of the curve, one can qualify relationship between curve and cycles in the strain based evolution which will provide base for the fatigue behaviour of the material evaluation. By conducting fatigue tests in various constant amplitude, the total longitude deformation and the residual deformation of the concrete will display the universal and the stable three-stage law, which presents rapid growth stage, the stable growth stage, and finally, ultimately the rapid growth stage respectively. The model is valid not only for the ordinary concrete, the lightweight aggregate concrete, the high strength concrete, or the fiber reinforced concrete, but also the compression fatigue, the tension fatigue, the bending fatigue, the uniaxial fatigue, or the multiracial fatigue. Chen et al. described the cubic polynomial curve fitting to highlights the correlation coefficients above 0.937 but different levels of stress had their own different coefficients of magnitudes. Cachim et al. proposed the logarithmic form between maximum strain rates with respect to number of load cycle for the second phase of the concrete. Under the compression fatigue loads, the form was a linear relationship. Xie et al. also found out the index formula for fitting of second phase of concrete regarding fatigue strain. Wang et al. conducted the compressive fatigue strain experiment for the achievement of two-staged nonlinear formula. On the base of fatigue strain revolution different methods of analysis showed much more deficiencies. Till date, the linear three-stage fatigue equations are described in good order of low. The three stage nonlinear equation is of high precision showed the complicated form. Due to lack of whole fatigue strain curve with cycle relationship, the fitting of fatigue strain curve with cyclic load relationship is advanced in recent researches. There have been few researches carried out in fatigue strain for conditions in which the fatigue stress is smaller than limited stress but greater than the threshold value $n$. A discussion has reached the variation law of the three-stage fatigue strain, and some different experienced curve fitting equations have been 
obtained, but the initial strain is not taken into consideration. The significance of factor related to fatigue strain is not clear enough which results the unstable fittings of coefficients.

The concrete is a complex hybrid composite material. During cyclic loading fracture may be occurred by fracturing of the cement paste, fracturing of the aggregate, failure of bond between the cement pastes aggregate or any combination of these mechanism. It contains voids and microcracks at the initial phase of preparation due to workability of concrete in presence of water before applying load. The fracture arised during cyclic loading due to increase in the stress concentration at the points of voids and microcracks. Forces that are required to obtain the fracture are usually much less than forces that would have been required in the case of monotonic loading. Fatigue is a process of damaging materials due to progressive permanent internal changes in the materials that occur under the actions of cyclic loadings. These phenomena can cause progressive growth of cracks present in the concrete molecular system and eventually fail structures when high levels of cyclic loads applied for shorter period of time or lower levels of loads are applied for longer periods times. This causes the failure of structure made of concrete with value lesser than the ultimate strength of the concrete. The Concrete, a heterogeneous material comprised of the mixture of cement, sand and aggregates, exhibits several mutually interacting inelastic mechanisms such as micro crack growth and inelastic flow even under small magnitude of cyclic load applied in large number of cycles. As a result, the concrete material does not guarantee endurance fatigue limit like metal as described by Miner's hypothesis.

The reinforced concrete structures such as bridges, hydraulic foundations, pressure vessels, crane beams are generally subjected to long term cyclic loading. The fatigue in concrete was experienced rather late, with comparison to steel. The fatigue resistance of the concrete is influenced by many different factors e.g. proportions in mixing ratios of manufacturing concrete, original moisture content, aggregate size, quality of sand, and load effects such as load frequency, nature of loading, axis of loading and maximum load level. During the hardening period setting period, air bubbles and micro-cracks are formed. The formation of microcracks is due to thermal strain, which is caused by temperature variation. When the micro-cracks propagates the fatigue process starts. At the beginning of the loading the propagation of the micro-cracks drives slowly. As loading continues the micro-cracks will proceed propagation and lead to macro-cracks, which may grow further. The macro-cracks in failure nature determine the remaining fatigue life caused by stress until failure occurs.

Depending on the range of the number of cycles to which a structure is subjected during service life, fatigue-prone structures may be grouped into three main classes, namely, low-cycle, high- cycle, and super-high cycle fatigue structures. The characteristic cyclic loads to which these structures are subjected to include vibrations, traffic loads, wind, and water waves. A low cycle fatigue is important for analysis point of view for structures subjected to earthquake loads (Nike and Ye, 1993). Three types of fatigue cycles are available in the literature i.e. (i) Low Cycle Fatigue having failure cycle 0 To $10^{3}$ and generally occurs in structures subjected to earthquake and storm (ii) High Cycle Fatigue having failure cycle $10^{3}$ To $10^{7}$ and generally occurs in the structures like Bridges, Airport Pavements, Wind Power Plants, Highway Pavements, Concrete Rail Road (iii) Super high cycle fatigue having failure cycle $10^{7}$ To $5 \times 10^{8}$ and generally occurs in the structures like Mass Rapid Structures, Sea Structures, and Machine Foundations. Since microcracks growth and inelastic flow would occur under small amplitude of cyclic load when applies for large number of cycles, the concrete does not guarantee endurance fatigue limit like metal as described in Miner's hypothesis (BriteEURamIII, 2000).

The presence of permanent damage at fatigue failure has been documented by a number of investigations. Szerszen (2013) developed fatigue damage model for ordinary concrete subjected to cyclic compression based on mechanics of composite materials utilizing the concept of dual nature of fatigue damage, which are cycle dependent and time dependent damage. The formulated model is capable of capturing the cyclic behavior of plain concrete due to progressive fatigue strain with the increase in number of loading 
cycles. Rao (2004) used accelerated pavement testing results to carry out cumulative fatigue damage analysis of concrete pavement. He reported that the Miner hypothesis does not accurately predict cumulative fatigue damage in concrete. The experimental work of Dyduch et.al., (1994) clearly showed that the increase of damage in the material takes place about last $20 \%$ of its fatigue life. ( Li et.al, (2004) presented a theoretical model to predict the fatigue process of concrete in alternate tension-compression fatigue loading using double bounding surface approach described in strainenergy release rate by constructing the damageeffective tensor.

In the past few years, a number of damage constitutive models have been published to model the observed mechanical behavior of concrete under monotonic and cyclic loading (Fardis, M.N., Alibi, B. and Tassoulas, J.L. , 1983), (Yang, B.L., Dafalias, Y.F., Herrmann, L.R., 1985 ), (Sauris, W., Ouyang, C., Fernando, V.M. , 1990), (Papa, E., 1993), (Khan, K.R., Al-Gadhib, A.H., Baluch, M.H , 1998 ), (Thapa, K.B., Yazdani, S. , 2013 ), . The constitutive models well describe the design of structural life arose from the physical observation of two dominant microstructural patterns of deformation in concrete having inelastic flow and microcracking natures. The inelastic flow factor of deformations is modeled by utilizing plasticity theories while the nucleation and propagation of microcracks and microvoids are incorporated in the constitutive models with the use of damage mechanics theories. The progressive development of cracks and microcracks alters the elastic properties (degradation of elastic moduli) due to energy dissipation and concrete material becomes more compliant.

This paper discusses the physical meanings, the ranges, and the impact on the shape of the curve of parameters by analyzing fatigue strain, fatigue modulus and damage in the nonlinear strain evolution model, fatigue strain modulus evolution model, damage strain evolution model, residual strain evolution model, strain linear model and the model regarding the hypothesis of thermodynamics. The evolution model of fatigue modulus was established under constant amplitude with the help of bending fatigue loading which is based on the fatigue strain evolution model and the relevant hypothesis of fatigue modulus which is inversely related to fatigue strain amplitude. A class of damage mechanics theory describes to model the fatigue damage and failure of concrete caused by multitude of numbers of microcracks, macrocracks through anisotropic damaging behavior which is captured through the use of proper response function involving damage parameter in material stiffness tensor. The increment of damage parameter in strain space is obtained from consistency equation proposed with respect to cycle dependent damage surface. The model is also capable of capturing the inelastic deformations that may arise due to misfits of crack surfaces and development of sizable crack tip process zone. Moreover, the whole process is validated by the experimental data also.

\section{Fatigue Strain Evolution Model}

Depending upon the different stress types, three-stage variation law of fatigue evolution model was proposed. Moreover, some valuable physical parameters like initial strain, instability speed of the third stage as a form of acceleration which is directly proportional to the total fatigue life of concrete. Mathematically, the model could be obtained as below

$\varepsilon^{n}=\varepsilon^{0}+\propto\left(\frac{\beta}{\beta-\frac{n}{N_{f}}}-1\right)^{1 / p}$

In formula (1), $\varepsilon^{0}=$ initial strain and $\varepsilon^{n}=$ fatigue strain, $n=$ cycle times of fatigue loads, $\boldsymbol{N}_{f}=$ the fatigue life. $\boldsymbol{\alpha}$, $\boldsymbol{\beta}$ and $\boldsymbol{p}$ were damage parameters due to materials defects in the equation.

If $\boldsymbol{\varepsilon}^{n}$ max or $\boldsymbol{\varepsilon}^{n}$ res was interpreted in the form of $\boldsymbol{\varepsilon}^{n}$, formula (1) can be modified. if the initial maximum strain $\varepsilon^{0}{ }_{\text {max }}$ or initial residual strain $\boldsymbol{\varepsilon}^{\mathbf{0}}$ res is regarded as the value of $\boldsymbol{\varepsilon}^{\mathbf{0}}$, formula (2) and (3) would be obtained

$$
\begin{aligned}
& \varepsilon_{\text {max }}^{n}=\varepsilon_{\text {max }}^{0}+\propto\left(\frac{\beta}{\beta-\frac{n}{N_{f}}}-1\right)^{1 / p} . \\
& \varepsilon_{\text {res }}^{n}=\varepsilon_{\text {res }}^{0}+\propto\left(\frac{\beta}{\beta-\frac{n}{N_{f}}}-1\right)^{1 / p}
\end{aligned}
$$


Equation (2) represents a formula for maximum strain and equation (3) represents the formula for the residual strain.

On the basis of the elastic proportional limit, if the upper limit of fatigue stress is larger then fatigue strain increases quickly. The slope of the curve regarding this increment will be larger and become vertical that causes the degeneration of the three-stage curve. When the upper limit of fatigue does not exceed the threshold value, the elastic strain should be added to the initial strain and value became unchanged, which shows similarity in the curve formulation. With the experimentation, it can be shown that the value of most stresses falls in between the value of threshold and upper limit.

Being the maximum and minimum value of stress and strain in fatigue test, two types of the curve regarding maximum strain i.e. $\boldsymbol{\varepsilon}^{\mathbf{0}}{ }_{\text {max }}$ and residual strain i.e. $\boldsymbol{\varepsilon}^{\mathbf{0}}$ res with respect to the cyclic number are obtained. The main causes for obtaining these two types of curve are due to defects in materials and preloading conditions. It is very much difficult to differentiate these two maximum and residual value, so experimentation of fatigue test has become essential.

Therefore, when the fatigue loading reaches to the upper limit then, the corresponding maximum strain $\boldsymbol{\varepsilon}^{1}{ }_{\max }$ and residual strain $\boldsymbol{\varepsilon}^{1}$ res are obtained which is adopted in this paper. For comparison, the obtained strain $\boldsymbol{\varepsilon}^{1}$ max and $\boldsymbol{\varepsilon}^{1}$ res compared to the actual experimental data i.e. $\boldsymbol{\varepsilon}^{\mathbf{1}}$ res $=\mathbf{0 . 2 5}$ $\left(\varepsilon_{\text {max }}^{1} / \varepsilon_{\text {unstable }}\right)^{2}$. In this formula, $\varepsilon_{\text {unstable is a total strain }}$ of concrete in an unstable state.

For the study of fatigue strain parameters $\alpha, \beta$ and $p$, on the basis of evolution law of fatigue strain curves, divided by fatigue strain in both side of formulas (4) and (5), we get

$$
\begin{aligned}
& \frac{\varepsilon_{\max }^{n}}{\varepsilon_{\max }^{f}}=\frac{\varepsilon_{\max }^{0}}{\varepsilon_{\max }^{f}}+\frac{\alpha}{\varepsilon_{\max }^{f}} \cdot\left(\frac{\beta}{\beta-\frac{n}{N_{f}}}-1\right)^{1 / p} \\
& \frac{\varepsilon_{\text {res }}^{n}}{\varepsilon_{\text {res }}^{f}}=\frac{\varepsilon_{\text {res }}^{0}}{\varepsilon_{\text {res }}^{f}}+\frac{\alpha}{\varepsilon_{\text {res }}^{f}} \cdot\left(\frac{\beta}{\beta-\frac{n}{N_{f}}}-1\right)^{1 / p}
\end{aligned}
$$

Equations (4) and (5) are the normalized fatigue strain evolution model. Where, $\varepsilon^{f}{ }_{\max }=$ limited maximum fatigue strain and $\varepsilon f_{\text {res }}=$ limited fatigue residual strain.

$\beta=$ destabilizing factor the value of which depends on $p$ and $\alpha$. If $n / N_{f}$ (Circulation ratio) is equal to 1 , the coordinate point $(1,1)$ will be adopted in formulas $(4)$ and (5), thus obtained the values of $\beta$ as formula (6) and (7), which is the maximum fatigue strain and the residual fatigue strain.

$$
\beta_{1}=\left(\frac{\left(1-\frac{\varepsilon_{\max }^{0}}{\varepsilon_{\max }^{f}}\right)}{\left(\frac{\propto}{\varepsilon_{\max }^{f}}\right)}\right)^{-p}+1
$$

$$
\beta_{2}=\left(\frac{\left(1-\frac{\varepsilon_{\text {res }}^{0}}{\varepsilon_{\text {res }}^{f}}\right)}{\left(\frac{\propto}{\varepsilon_{\text {res }}^{f}}\right)}\right)^{-p}+1
$$

From equation (4) impacts of $\boldsymbol{p}$ and $\boldsymbol{\alpha}$ on the fatigue, the strain evolution curve can be calculated. At first, the impact of $\boldsymbol{p}$ was analyzed i.e. $\varepsilon^{0}{ }_{\text {max }} / \varepsilon^{f_{\text {max }}}$ and $\alpha / \varepsilon^{f_{\text {max }}}$. After that, combined with $p$ and $\varepsilon_{\text {max }}^{0} / \varepsilon^{f_{\text {max }}}$, the impact of $\boldsymbol{\alpha}$ was further calculated. The curve regarding the impact of $\boldsymbol{p}$ and $\boldsymbol{\alpha}$ were shown in Figures (1) and (2).

It is obviously shown that the rate of convergence speed of $\mathrm{p}$ influences the convergence speed of curve in $\mathrm{S}$ nonlinear model. The instability speed factor increased at the faster increment of $\mathrm{P}$ when the third stage of the curve will grow faster. Therefore, the factor $\mathrm{p}$ should be located in the curve.

The parameter $\alpha$ values on the curve shall also affect the curve in the sense of total fatigue life of the material which shall be shown in the third stage of the nonlinear curve. After increasing of $\boldsymbol{\alpha}$, the part of acceleration shall become shorter. $\alpha / \varepsilon f \max$ is located corresponding to $(\mathbf{0}$, $1-\varepsilon^{0}{ }_{\text {max }}\left(\varepsilon^{f_{\text {max }}}\right)$, whereas, $\boldsymbol{\alpha}$ was placed in the comparison of $\left(0, \varepsilon f_{\max }-\varepsilon^{0}\right.$ max $)$. The obtained value of the parameters $\alpha, \beta$ and $p$ are mainly aimed which is found in b-type curves having three stages of evolutions. Therefore, it can be imagined that the values for both type curve are not limited by the literature. By modeling, S-shaped curves contents various parameters including different kinds of fatigue strain evolutions at the different stages for the concrete material. 


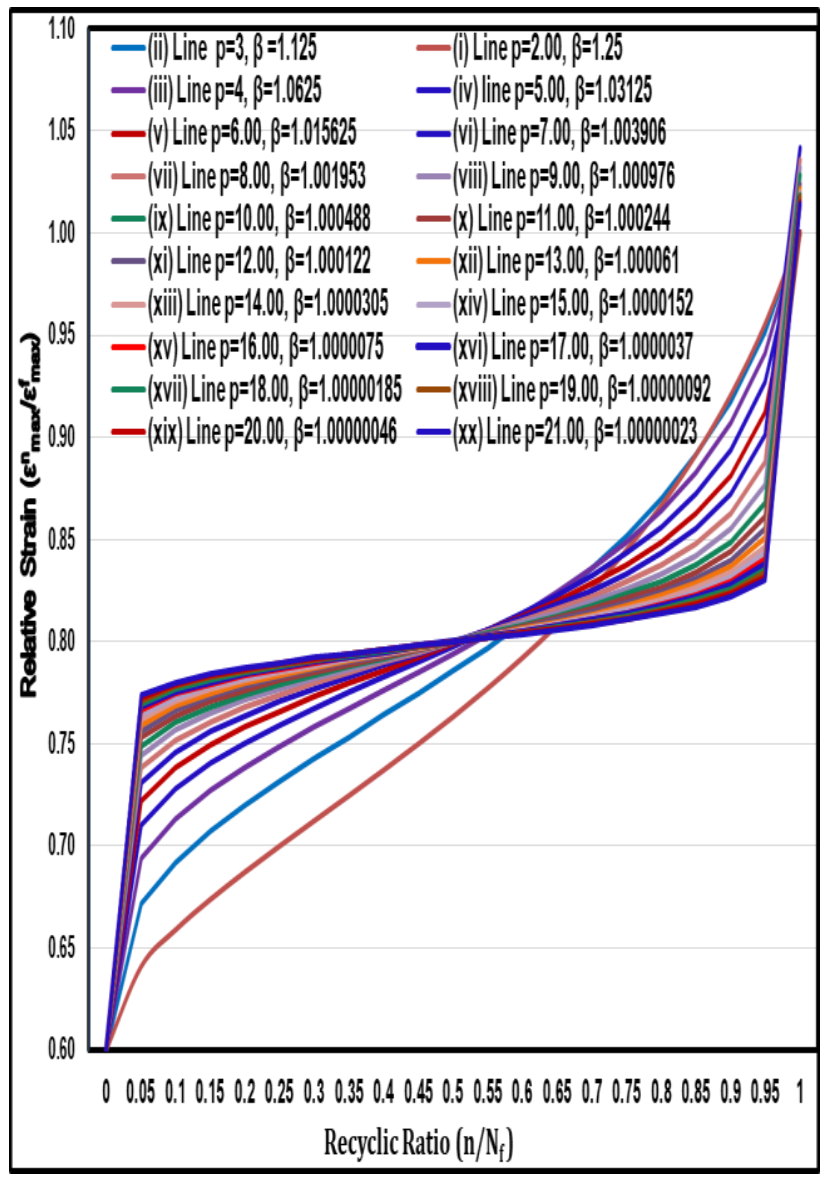

Figure 1. Concrete Fatigue Strain Evolution, Influence of Fatigue Strain Parameter " $p$ " on Fatigue Strain Curve by Putting the value of (i) $p=2.00$, $\beta=1.25$ (ii) $p=3.00, \beta=1.125$ (iii) $p=4.00, \beta=1.0625$ (iv) $\mathrm{p}=5.00, \beta=1.0315$ (v) $\mathrm{p}=6.00, \beta=1.015625$ (vi) $\mathrm{p}=7.00, \beta=1.003906$ (vii) $\mathrm{p}=8.00, \beta=1.001953$ (viii) $p=9.00, \beta=1.000976$ (ix) $p=10.00, \beta=1.000488$ (x) $\mathrm{p}=11.00, \quad \beta=1.000244$ (xi) $\mathrm{p}=12.00, \beta=1.000122$ (xii) $\mathrm{p}=13.00, \quad \beta=1.000061 \quad$ (xiii) $\mathrm{p}=14.00$, $\beta=1.0000305$ (xiv) $p=15.00, \quad \beta=1.0000152 \quad$ (xv) $p=16.00, \beta=1.0000075$ (xvi) $p=17.00, \beta=1.0000037$ (xvii) $\mathrm{p}=18.00, \beta=1.00000185$ (xviii) $\mathrm{p}=19.00$, $\beta=1.00000092$ (xix) $p=20.00, \beta=1.00000046$ (xx) $\mathrm{p}=21.00, \beta=1.00000023$ and $\boldsymbol{\varepsilon}^{\mathbf{0}}{ }_{\max } / \boldsymbol{\varepsilon}_{\text {max }}^{\mathrm{f}}=\mathbf{0 . 6 0}$ and $\propto / \varepsilon_{\text {max }}^{\mathrm{f}}=\mathbf{0 . 2 0}$

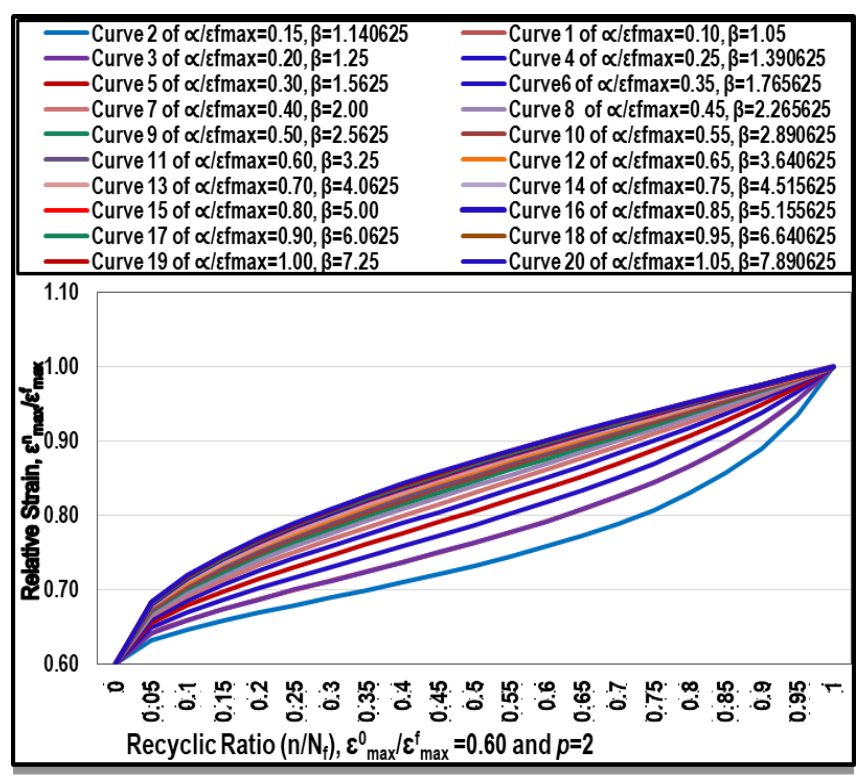

Figure 2. Concrete Fatigue Strain Evolution, Influence of Fatigue Strain Parameter " $\alpha$ " on Fatigue Strain Curve, Putting the value of (i) $\propto / \varepsilon_{\text {max }}^{\mathbf{f}}=0.10$ to $1.05, \beta=1.05$ to 7.890625 and $\boldsymbol{\varepsilon}^{\mathbf{0}}{ }_{\text {max }} / \boldsymbol{\varepsilon}_{\text {max }}^{\mathbf{f}}=\mathbf{0 . 6 0}, \boldsymbol{p = 2}$ constant in all cases

—Family Curve 1, $\varepsilon 0 \max / \varepsilon f \max =0.70, p=2, \alpha / \varepsilon f \max =0.25, \beta=1.694444$

—Family Curve 2, $\varepsilon 0 \max / \varepsilon f \max =0.65, p=3, \alpha / \varepsilon f \max =0.23, \beta=1.283778$

—Family Curve 3, $\varepsilon 0 \max / \varepsilon f \max =0.60, p=4, \alpha / \varepsilon f \max =0.19, \beta=1.050907$

—Family Curve 4, $\varepsilon 0 \max / \varepsilon f \max =0.55, p=5, \alpha / \varepsilon f \max =0.17, \beta=1.007695$

-Family Curve 5, $\varepsilon 0 \max / \varepsilon f \max =0.50, p=6, \alpha / \varepsilon f \max =0.15, \beta=1.000729$

-Family Curve 6, $\varepsilon 0 \max / \varepsilon f \max =0.45, p=7, \alpha / \varepsilon f \max =0.13, \beta=1.000041$

—Family Curve 7, $\varepsilon 0 \max / \varepsilon f \max =0.40, p=8, \alpha / \varepsilon f \max =0.11, \beta=1.000001$

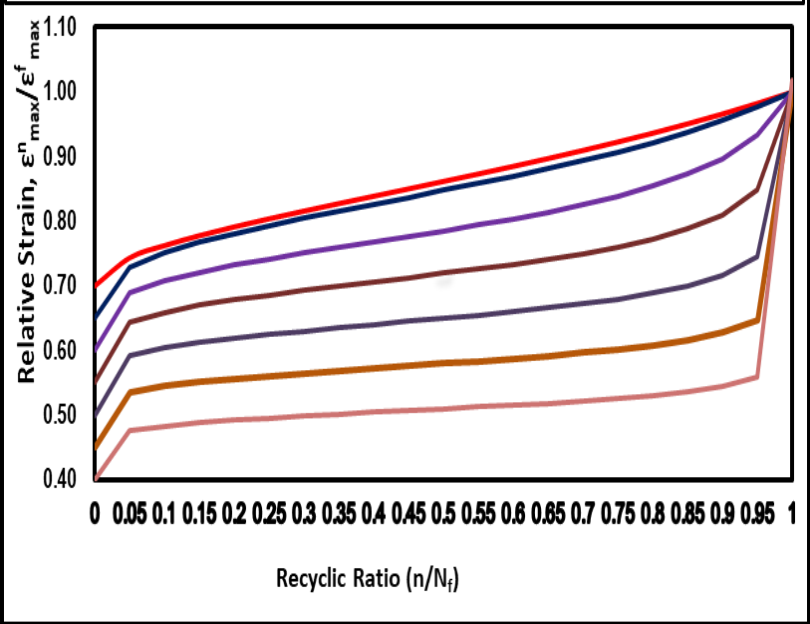

Figure 3. Concrete Fatigue Strain Evolution, Family Strain Curve (i) $\varepsilon^{0}{ }_{\text {max }} / \varepsilon^{\mathrm{f}}{ }_{\max }=0.70, p=2.00$, $\propto / \varepsilon_{\text {max }}^{\mathrm{f}}=0.25, \beta=1.694444$ (ii) $\quad \varepsilon^{0}{ }_{\text {max }} / \varepsilon^{\mathrm{f}}$ max $=0.65$, $p=3.00, \propto / \varepsilon_{\text {max }}^{\mathrm{f}}=0.23, \beta=1.283778$ (iii) $\quad \varepsilon_{\text {max }}^{0} / \varepsilon_{\text {max }}^{\mathrm{f}}$ 
$=0.60, \quad p=4.00, \quad \propto / \varepsilon_{\text {max }}^{\mathrm{f}}=0.19, \quad \beta=1.050907 \quad$ (iv) $\varepsilon_{\text {max }}^{0} / \varepsilon_{\text {max }}^{\mathrm{f}}=0.55, p=5.00, \propto / \varepsilon_{\text {max }}^{\mathrm{f}}=0.17, \beta=1.007695$ (v) $\quad \varepsilon_{\text {max }}^{0} / \varepsilon_{\text {max }}^{\mathrm{f}}=0.50, \quad p=6.00, \propto / \varepsilon_{\text {max }}^{\mathrm{f}}=0.15$, $\beta=1.000729 \quad$ (vi) $\quad \varepsilon_{\text {max }}^{0} / \varepsilon_{\text {max }}^{\mathrm{f}}=0.45, p=7.00$, $\propto / \varepsilon_{\text {max }}^{\mathrm{f}}=0.13, \beta=1.000041$ (vii) $\varepsilon^{0}{ }_{\text {max }} / \varepsilon^{\mathrm{f}}{ }_{\text {max }}=0.40$, $p=8.00, \propto / \varepsilon_{\text {max }}^{\mathrm{f}}=0.11, \beta=1.000001$

\section{Fatigue Modulus Evolution Model}

Mathematically Fatigue Modulus i.e. "E" is defined as,

$\boldsymbol{E}=\left(\frac{\sigma_{\max }-\sigma_{\min }}{\varepsilon_{\max }-\varepsilon_{\min }}\right)$

Where, $\sigma_{\max }=$ Maximum Stress and $\sigma_{\min }=$ minimum fatigue stresses. At constant amplitude fatigue loads, stress amplitude $\sigma_{\max }-\sigma_{\min }$ remains unchanged. Therefore, the fatigue modulus and fatigue strain amplitude are an inversely proportional; that is, the fatigue modulus increases when the fatigue strain decreases. The strain evolution curve is the level-Sshaped curve reversed as the curve of fatigue modulus shown in Figure (4). Suppose two curves are symmetrical about the straight line, parallel to $\mathrm{X}$-axis, $y=D$, and the point in the fatigue strain curve is $(x$, $y)$. Therefore, corresponding point on the curve of the fatigue modulus is $(x, 2 D-y)$. Therefore, the normalized fatigue modulus can be expressed as:

$\frac{E^{n}}{E_{0}}=\frac{E_{0}}{E^{f}}+\frac{\alpha^{\prime}}{\varepsilon^{f}}\left(\frac{\beta^{\prime}}{\beta^{\prime}-\frac{n}{N f}}-1\right)^{\frac{1}{p^{\prime}}}+2 D$

The mathematical formula for fatigue modulus evaluation model is

$E^{n}=E_{0}\left(\frac{E_{0}}{E^{f}}+\frac{\alpha^{\prime}}{g^{f}}\left(\frac{\boldsymbol{\beta}^{\prime}}{\boldsymbol{\beta}^{\prime}-\frac{\boldsymbol{n}}{N \boldsymbol{f}}}-1\right)^{\frac{1}{p^{\prime}}}+2 \boldsymbol{D}\right)$

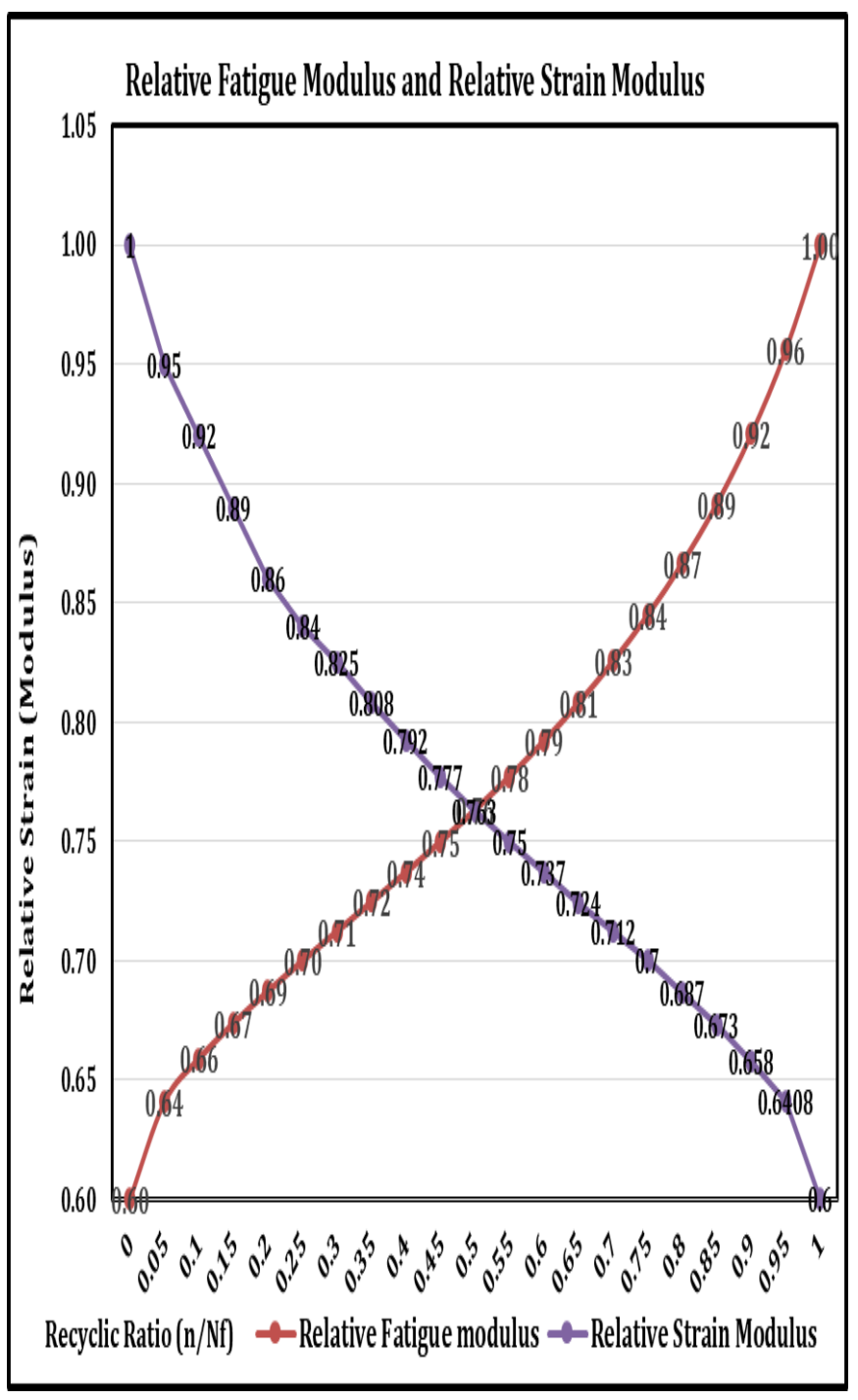

Figure 4. Concrete Fatigue Strain Evolution, Strain Modulus, value inserted to obtain the curve, $\varepsilon_{\text {max }}^{0} / \varepsilon_{\text {max }}^{\mathrm{f}}=0.60, \quad p=2.00, \quad \propto / \varepsilon_{\text {max }}^{\mathrm{f}}=0.20, \quad \beta=1.25$ (Relative Strain is inversely related to Fatigue Modulus)

\section{Fatigue Damage Evolution Model}

Before performing the fatigue test experiment, preloading test should be done to realize the upper limit of fatigue load which creates the damage. Initial damage is categorized in two parts, i.e. damage caused by the material defects and the damage caused by application of load. After achievement of clear concept of above said mechanism, damage regarding maximum fatigue strain during shock and vibration can be written as; 
$D=\left\{\begin{array}{c}D_{0}=\frac{\varepsilon_{\max }^{0}}{\varepsilon_{\max }^{f}} \\ D_{0}+\frac{\varepsilon_{\max }^{n}-\varepsilon_{\max }^{0}}{\varepsilon_{\max }^{f}}\end{array}\right.$

Where, $D 0=$ initial damage. Adopting the fatigue strain evolution formula from equation (2) into equation (11), the damage evolution equation based on the maximum fatigue strain is developed. The damage evolution formula is as under:

$$
D=\left\{\begin{array}{c}
D_{0}=\frac{\varepsilon_{\max }^{0}}{\boldsymbol{\varepsilon}_{\max }^{\boldsymbol{f}}} \\
D_{0}+\frac{\propto \dot{ }}{\boldsymbol{\varepsilon}_{\max }^{f}} \cdot\left(\frac{\boldsymbol{\beta}^{\prime}}{\boldsymbol{\beta}^{\prime}-\frac{\boldsymbol{n}}{\boldsymbol{N} \boldsymbol{f}}}-1\right)^{\frac{1}{\boldsymbol{p}^{\prime}}}
\end{array}\right.
$$

if $\alpha^{\prime} / \varepsilon^{f} \max =m$, then the above equation changes

$$
D=\left\{\begin{array}{c}
D_{0}=\frac{\varepsilon_{\max }^{\mathbf{o}}}{\boldsymbol{\varepsilon}_{\max }^{f}} \\
D_{0}+\boldsymbol{m} \cdot\left(\frac{\boldsymbol{\beta}^{\prime}}{\boldsymbol{\beta}^{\prime}-\frac{\boldsymbol{n}}{\boldsymbol{N} \boldsymbol{f}}-1}\right)^{\frac{1}{\boldsymbol{p}^{\prime}}} .
\end{array}\right.
$$

Similarly, by definition, damage based on fatigue residual strain can be expressed as under:

$$
D=\left\{\begin{array}{c}
D_{0}=\frac{\varepsilon_{\text {res }}^{0}}{\varepsilon_{\text {res }}^{f}} \\
D_{0}+\frac{\varepsilon_{\text {res }}^{n}-\varepsilon_{\text {res }}^{0}}{\varepsilon_{\text {res }}^{f}} .
\end{array}\right.
$$

Putting the value of fatigue residual strain evolution formula from equation (3) into equation (14), the damage evolution equation based on the fatigue residual strain is generated. The expression is as follows:

$$
D=\left\{\begin{array}{c}
D_{0}=\frac{\varepsilon_{\text {res }}^{0}}{\varepsilon_{\text {res }}^{f}} \\
D_{0}+\frac{\propto^{\prime}}{\varepsilon_{\text {res }}^{f}} \cdot\left(\frac{\boldsymbol{\beta}^{\prime}}{\boldsymbol{\beta}^{\prime}-\frac{\boldsymbol{n}}{\boldsymbol{N} \boldsymbol{f}}}-1\right)^{\frac{1}{p^{\prime}}} .
\end{array}\right.
$$

For Data fittings, if $\alpha^{\prime} / \varepsilon^{f}$ res $=n$, then the above equation becomes,

$$
D=\left\{\begin{array}{c}
D_{0}=\frac{\varepsilon_{\text {res }}^{0}}{\boldsymbol{\varepsilon}_{\text {res }}^{f}} \\
D_{0}+\boldsymbol{n} \cdot\left(\frac{\boldsymbol{\beta}^{\prime}}{\boldsymbol{\beta}^{\prime}-\frac{\boldsymbol{n}}{\boldsymbol{N} \boldsymbol{f}}-1}\right)^{\frac{1}{p^{r}}}
\end{array}\right.
$$

It is clearly shown that at the increment of concrete damage circulation ratio, the concrete damage grows rapidly to the middle stage linearly which is similar to strain evolution, it has at wastage variation.

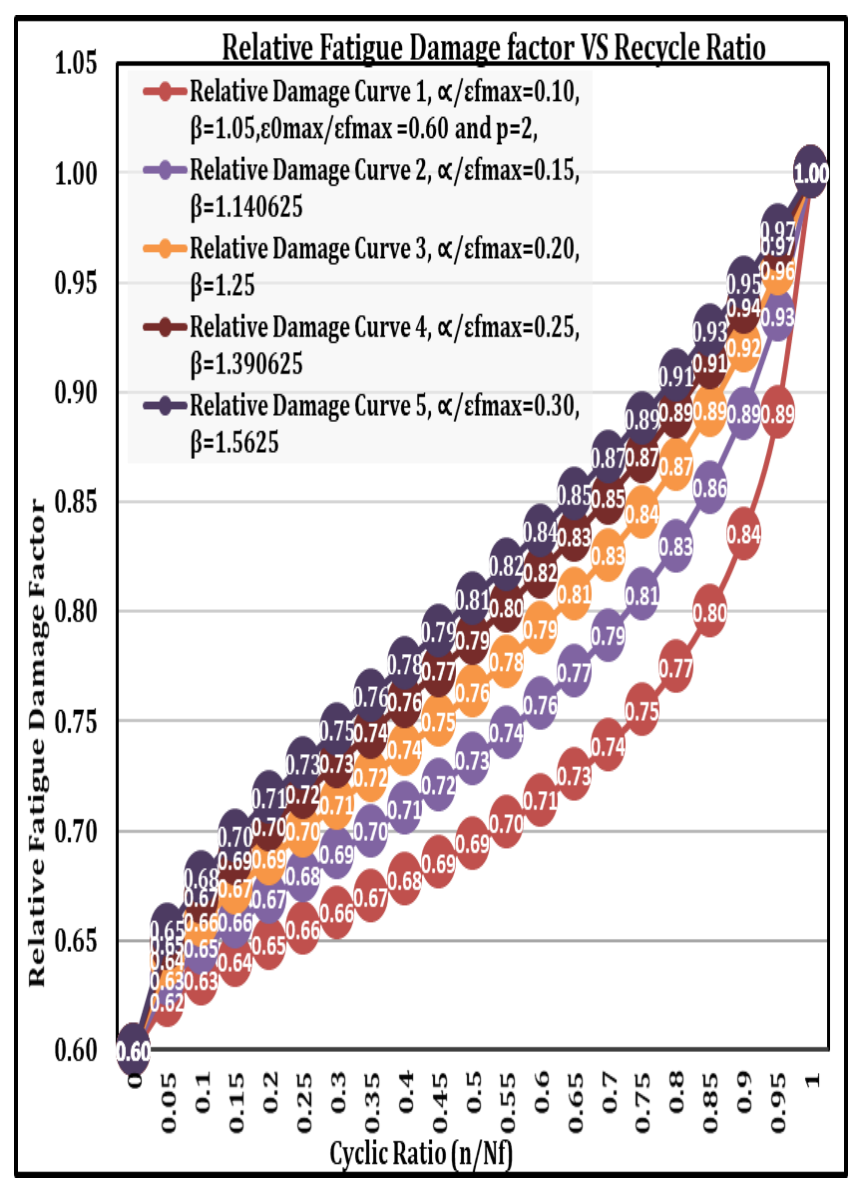

Figure 6. Concrete Fatigue Strain Evolution, Relative fatigue Damage (i) $\varepsilon^{0}{ }_{\text {max }} / \varepsilon_{\text {max }}^{\mathrm{f}}=0.60$, $p=2.00, \propto / \varepsilon_{\text {max }}^{f}=0.10, \beta=1.05$ (ii) $\varepsilon_{\text {max }}^{0} / \varepsilon_{\text {max }}^{f}=0.60$, $p=2.00, \propto / \varepsilon_{\text {max }}^{f}=0.15, \beta=1.140625$ (iii) $\varepsilon_{\text {max }}^{0} / \varepsilon_{\text {max }}^{\mathrm{f}}$ $=0.60, p=2.00, \propto / \varepsilon_{\text {max }}^{\mathrm{f}}=0.20, \beta=1.25$ (iv) $\varepsilon_{\text {max }}^{0} / \varepsilon_{\text {max }}^{\mathrm{f}}$ $=0.60, \quad p=2.00, \quad \propto / \varepsilon_{\text {max }}^{\mathrm{f}}=0.25, \quad \beta=1.390625 \quad$ (v) $\varepsilon_{\text {max }}^{0} / \varepsilon_{\text {max }}^{\mathrm{f}}=0.60, p=2.00, \propto / \varepsilon_{\text {max }}^{\mathrm{f}}=0.30, \beta=1.5625$ 


\section{Fatigue Damage Model in strain space by using the general framework of internal variable theory of continuum thermodynamics.}

For isothermal process, rate independent behavior and small deformations, the Helmholtz Free Energy (HFE) per unit volume can be deduced as follows:

$$
\mathrm{A}(\boldsymbol{\varepsilon}, \mathrm{k})=\frac{1}{2} \boldsymbol{\varepsilon}: \mathbf{E}(k): \boldsymbol{\varepsilon}-\dot{\boldsymbol{\sigma}}^{\mathrm{i}}: \boldsymbol{\varepsilon}+\mathrm{A}^{\mathrm{i}}(k)
$$

Where $\mathbf{E}(\mathrm{k})$ represents fourth order elastic stiffness tensor which depends on the state of microcracking (damage), $\boldsymbol{\varepsilon}$ is the strain tensor, $\boldsymbol{\sigma}^{\mathbf{i}}$ denotes the stress tensor corresponding to inelastic damage. The term $A^{i}(k)$ represents surface energy of microcracks, and $\mathrm{k}$ is the cumulative fatigue damage parameter. The colon (:) represents the tensor contraction operation.

Utilizing fourth order material's stiffness tensors, the stress regarding damage process is given by mathematical relations:

$$
\boldsymbol{\sigma}=\frac{\partial A}{\partial \boldsymbol{\varepsilon}}=\mathbf{E}(k): \boldsymbol{\varepsilon}-\boldsymbol{\sigma}^{i}(k)
$$

The first derivative form of Eqn (2) with respect to cyclic number $\mathrm{N}$ is given by

$$
\begin{aligned}
\dot{\boldsymbol{\sigma}} & =\mathbf{E}(k): \dot{\boldsymbol{\varepsilon}}+\dot{\mathbf{E}}(k): \boldsymbol{\varepsilon}-\dot{\boldsymbol{\sigma}}^{i}(k) \\
& =\dot{\boldsymbol{\sigma}}^{\mathbf{e}}+\dot{\boldsymbol{\sigma}}^{\mathbf{D}}(k)+\dot{\boldsymbol{\sigma}}^{\mathbf{i}}(k)
\end{aligned}
$$

Where $\dot{\boldsymbol{\sigma}}^{\mathbf{e}}$ is the stress increment in the absence of further damage in the material, $\dot{\boldsymbol{\sigma}}^{\mathbf{D}}$ is the rate of stressrelaxation due to further microcracking (elastic damage), and $\dot{\boldsymbol{\sigma}}^{\mathbf{i}}(k)$ designates the rate of stress tensor to the solid body which is irrecoverable or permanent deformation due to microcracking.

The assumption is made such that damage during fatigue loading alters elastic properties and affects the stiffness tensor. For small deformation, the following decomposition of the fourth-order stiffness tensor, E, is adopted.

$$
\frac{\partial^{2} A}{\partial \boldsymbol{\varepsilon} \partial \boldsymbol{\varepsilon}}=\mathbf{E}(k)=\mathbf{E}^{0}+\mathbf{E}^{\mathbf{D}}(k)
$$

Where $\mathbf{E}^{\mathbf{0}}$ is stiffness of the undamaged or virgin material and $\mathbf{E}^{\mathbf{D}}(k)$ denotes the overall stiffness degradation caused by damage during fatigue loadings. Further, $\dot{\mathbf{E}}(k)$ and $\dot{\boldsymbol{\sigma}}^{\mathrm{i}}(k)$ are expressed as fluxes in the thermodynamic state sense and are expressed in terms of evolutionary equations as

$$
\dot{\mathbf{E}}^{\mathbf{D}}=-\dot{\mathrm{k}} \mathbf{L} \quad \text { and } \quad \dot{\boldsymbol{\sigma}}^{i}=\dot{\mathrm{k}} \mathbf{M}
$$

Where $\mathbf{L}$ and $\mathbf{M}$ are fourth and second order response tensors that determine the directions of the elastic and inelastic damage processes. Following the ClausiusDuhem inequality, utilizing the standard thermodynamic arguments [5] and assuming that the unloading is an elastic process, a potential function

$$
\Psi(\boldsymbol{\varepsilon}, k)=\frac{1}{2} \boldsymbol{\varepsilon}: \mathbf{L}: \boldsymbol{\varepsilon}-\mathbf{M}: \boldsymbol{\varepsilon}-\frac{1}{2} p^{2}(\boldsymbol{\varepsilon}, k)=0 \text {. }
$$

Equation (6) is obtained in damage surface which establishes the onset of material inelasticity and stiffness reduction. In equation (6), $p(\boldsymbol{\varepsilon}, k)$ is interpreted as the damage function given below as

$$
p^{2}(\boldsymbol{\varepsilon}, k)=2\left[h^{2}(\boldsymbol{\varepsilon}, k)+\frac{\partial A^{i}}{\partial k}\right]
$$

for some scalar valued function $h^{2}(\varepsilon, k)$. It should be noted that as long as the function $p^{2}(\boldsymbol{\varepsilon}, k)$ is defined, the individual terms on the R.H.S of equation (7) need not to be identified.

To establish the specific forms of response tensors $\mathbf{L}$ and $\mathbf{M}$, it is necessary to determine a proper relation for the response tensor, is decomposed as positive and negative cones. The positive and negative nature of the strain tensor hold the corresponding positive and negative eigenvalue of the whole entire structural system, that is, $\boldsymbol{\varepsilon}=\boldsymbol{\varepsilon}^{+}+\boldsymbol{\varepsilon}^{-}$. Here, $\boldsymbol{\varepsilon}^{+}$and $\boldsymbol{\varepsilon}^{-}$represent the positive and negative cones of the strain tensor, respectively. Based on the experimental observations and results for concrete materials, damage is assumed to occur in the cleavage mode of cracking as shown schematically in Figure 1. 


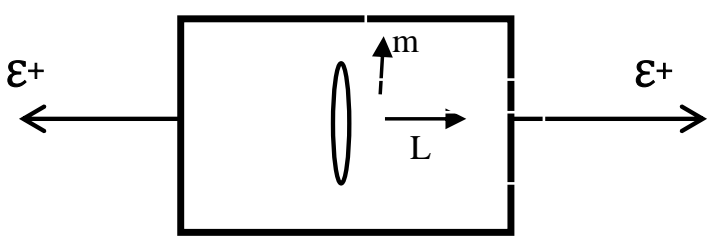

Figure 7 Schematic representation of mode I damage (crack opening in tensile mode) under cyclic tension.

For cleavage cracking mode, the response tensors are postulated for $\mathbf{L}$ and $\mathbf{M}$

$$
\mathbf{L}=\frac{\boldsymbol{\varepsilon}^{+} \otimes \boldsymbol{\varepsilon}^{+}}{\boldsymbol{\varepsilon}^{+}: \boldsymbol{\varepsilon}^{+}}
$$

$$
\mathbf{M}=\beta \boldsymbol{\varepsilon}^{+}
$$

The substitution of response tensors $\mathbf{L}$ and $\mathbf{M}$ from equations (8) and (9) into equation (6) leads to the final form of the damage surface

$$
\begin{array}{r}
\Psi(\boldsymbol{\varepsilon}, k)=\frac{1}{2} \boldsymbol{\varepsilon}: \frac{\boldsymbol{\varepsilon}^{+} \otimes \boldsymbol{\varepsilon}^{+}}{\boldsymbol{\varepsilon}^{+}: \boldsymbol{\varepsilon}^{+}}: \boldsymbol{\varepsilon}-\beta \boldsymbol{\varepsilon}^{+}: \boldsymbol{\varepsilon} \\
-\frac{1}{2} p^{2}(\boldsymbol{\varepsilon}, k)=0
\end{array}
$$

For fatigue tensile loading the damage surface of equations (10a) is rewritten as

$$
\begin{aligned}
\Psi(\boldsymbol{\varepsilon}, k) & =\frac{1}{2} \boldsymbol{\varepsilon}^{+}: \boldsymbol{\varepsilon}^{+}-\beta \boldsymbol{\varepsilon}^{+}: \boldsymbol{\varepsilon}^{+}-\frac{1}{2} p^{2}(\boldsymbol{\varepsilon}, k)=0 \\
& =\frac{1}{2} \boldsymbol{\varepsilon}^{+}: \boldsymbol{\varepsilon}^{+}(1-2 \beta)-\frac{1}{2} p^{2}(\boldsymbol{\varepsilon}, k)=0 \ldots
\end{aligned}
$$

The damage function $\mathrm{p}(\mathrm{k})$ obtained from uniaxial tensile test for concrete materials based on the experimental results of (14) is given in (15) as

$$
\mathrm{p}(k)=\varepsilon_{\mathrm{u}} \ln \left(\frac{\mathrm{E}^{0}}{\mathrm{E}^{0}-\mathrm{k}}\right)
$$

And for elastic damaging process, $(\beta=0)$, the limit damage surface reduces to

$\mathrm{p}(k)=\varepsilon_{\mathrm{u}}$

Where $\varepsilon_{\mathrm{u}}$ represents the strain corresponding to uniaxial tensile strength of concrete, which is used as the reference strain and hence the result of a conventional uniaxial tensile test is needed to establish $\varepsilon_{\mathrm{u}}$.
The behaviour of concrete material due to fatigue strain applying goes progressive permanent structural change and the material fails at stresses having a maximum value less than the tensile strength of the material. In this paper, it is assumed that within the damage surface of the given strain state, the unloadingreloading cycles (Fatigue loadings), increase amount of damage of concrete due to the growth of microcracks leading to inelastic deformations and stiffness degradation, which eventually reduces the ultimate molecular strength of the concrete. To achieve this, the damage surface $\Psi(\boldsymbol{\varepsilon}, k)$ is modified to predict the increase in damage in the material with increasing number of cycles of loading as

$$
\frac{1}{2} \boldsymbol{\varepsilon}^{+}: \boldsymbol{\varepsilon}^{+}(1-2 \beta) X(N)-\frac{1}{2} p^{2}(\boldsymbol{\varepsilon}, k)=0
$$

Where $X(N)$ is a function that depends on the number of loading cycles and adopted to increase of damage with increasing number of cycles. We propose a power function for $\mathrm{X}(\mathrm{N})$ as

$$
X(N)=N^{A}
$$

Here, $\mathrm{N}$ represents the number of loading cycles, and $\mathrm{A}$ is a material parameter. Utilizing equations (28) through (14), we obtain the cumulative fatigue parameter $\mathrm{k}$ as

$$
k=E^{0}\left[1-\frac{1}{\exp \left(\frac{\sqrt{(1-2 \beta) N^{A} \boldsymbol{\varepsilon}^{+}: \boldsymbol{\varepsilon}^{+}}}{\varepsilon_{\mathrm{u}}}\right)}\right]
$$

By differentiating equation (15) with respect to $\mathrm{N}$, the increment of damage in one cycle is obtained as

$$
\begin{aligned}
& \dot{k}=\frac{d k}{d N} \\
& =\frac{A N^{\frac{A}{2}-1} E^{0} \sqrt{\boldsymbol{\varepsilon}^{+}: \boldsymbol{\varepsilon}^{+}(1-2 \beta)}}{2 \varepsilon_{u} \exp \left(-\sqrt{\boldsymbol{\varepsilon}^{+}: \boldsymbol{\varepsilon}^{+}(1-2 \beta) N^{A} / \varepsilon_{u}^{2}}\right)}
\end{aligned}
$$

Finally, the rate of damage parameter, $\dot{\mathrm{k}}$, must be used in the simple constitutive relation of the form given by equation (3) in uniaxial tensile stress path for representing inelastic deformation, stiffness degradation 
and strength reduction due to fatigue strain. Substituting equations (8), (9) and (16) into equation (5) and then substituting Eqns (4) and (5) into equation (3) yields

$$
\dot{\boldsymbol{\sigma}}=\mathbf{E}(k): \dot{\boldsymbol{\varepsilon}}-\dot{k}\left(\frac{\boldsymbol{\varepsilon}^{+} \otimes \boldsymbol{\varepsilon}^{+}}{\boldsymbol{\varepsilon}^{+}: \boldsymbol{\varepsilon}^{+}}: \boldsymbol{\varepsilon}+\beta \boldsymbol{\varepsilon}^{+}\right)
$$

Equations (17) is the rate of change of stress tensor for uniaxial tension-tension fatigue loading, by keeping in assumptions that unloading is elastic. When, $\beta=0$, the process is termed as elastic-damaging, in which stress-strain curve returns to origin upon unloading of the material. In fact, damage incurred in concrete cannot be considered perfectly elastic, i.e. the value of beta cannot be zero. The unloaded material shows some residual strains due to the development of sizable crack tip process zone and misfits of the crack surfaces.

For uniaxial tension, equation (17) becomes

$$
\dot{\boldsymbol{\sigma}}=\mathbf{E}: \dot{\boldsymbol{\varepsilon}}-\left[\frac{A N^{\frac{A}{2}-1} E^{0} \sqrt{\boldsymbol{\varepsilon}^{+}: \boldsymbol{\varepsilon}^{+} \eta}((1+\beta))}{2 \varepsilon_{u} \exp \left(-\sqrt{\frac{\boldsymbol{\varepsilon}^{+}: \boldsymbol{\varepsilon}^{+} \eta N^{A}}{\varepsilon_{u}^{2}}}\right)}\right] \boldsymbol{\varepsilon}^{+} \ldots
$$

Where, $\eta=1-2 \beta$.

Parameters could be obtained via the model, such as the initial strain, instability speed of the third stage (acceleration of fatigue strain), and the proportion that in the total fatigue life on the basis of repeated load

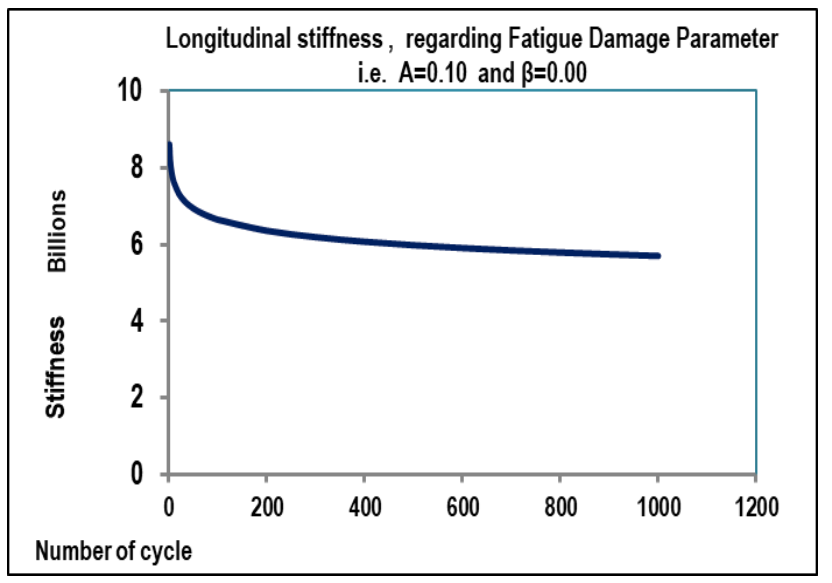

Figure 8. Model prediction of stiffness reduction with number of cyclic loading. Adopting the Value of Fatigue Damage Parameter, $\mathrm{A}=0.10$ and $\beta=0.00$

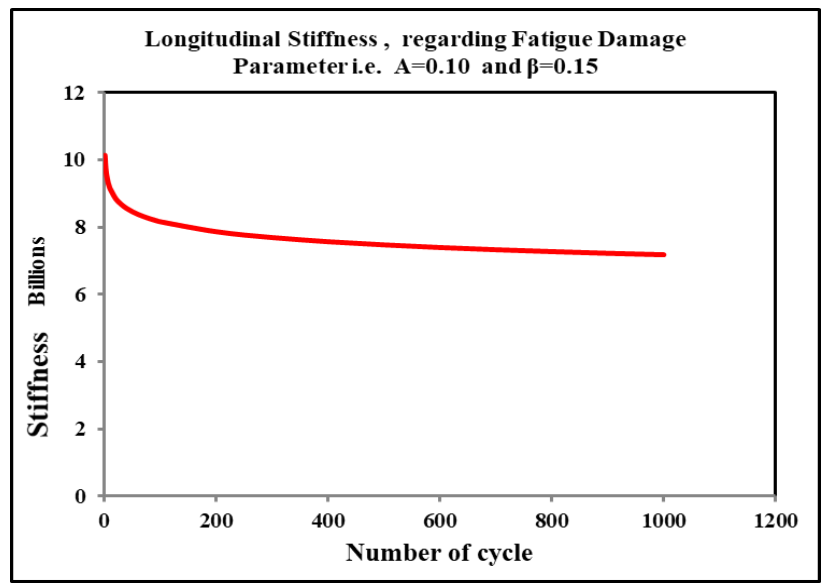

Figure 9. Model prediction of stiffness reduction with number of cyclic loading. Adopting the Value of Fatigue Damage Parameter, $\mathrm{A}=0.10$ and $\beta=0.15$

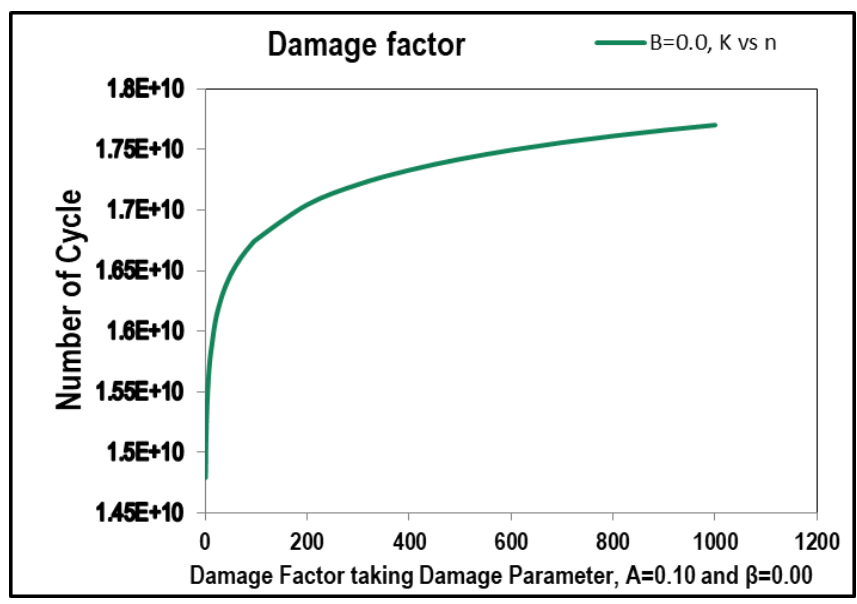

Figure 10. Model prediction of Damage Factor with number of cyclic loading. Adopting the Value of Fatigue Damage Parameter, $\mathrm{A}=0.10$ and $\beta=0.00$

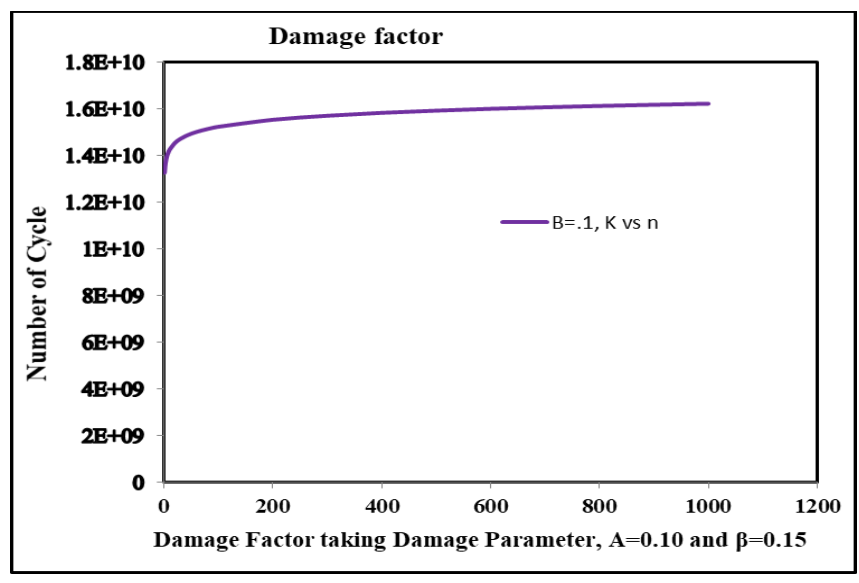

Figure 11. Model prediction of Damage Factor with number of cyclic loading. Adopting the Value of Fatigue Damage Parameter, $\mathrm{A}=0.10$ and $\beta=0.15$ 


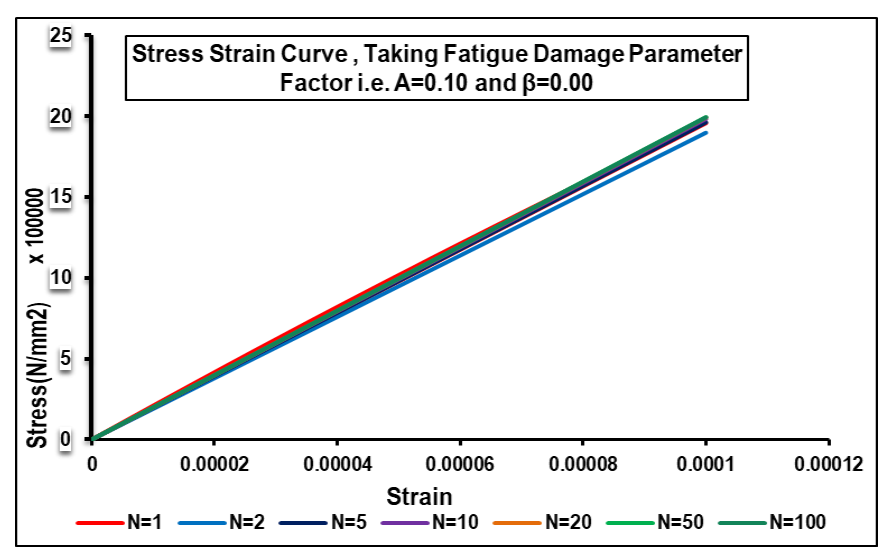

Figure 12. Theoretical cyclic stress-strain behavour of concrete during elastic damaging process under uniaxial fatigue loading. Adopting the Value of Fatigue Damage Parameter. $\mathrm{A}=0.10$ and $\beta=0.00$

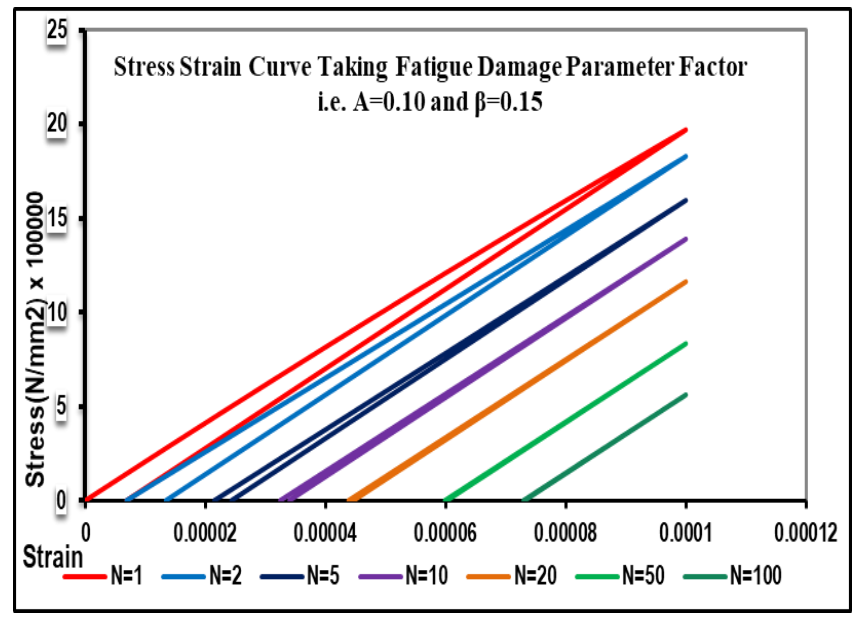

Figure 13. Theoretical cyclic stress-strain behavour of concrete during elastic damaging process under uniaxial fatigue loading. Adopting the Value of Fatigue Damage Parameter, $\mathrm{A}=0.10$ and $\beta=0.15$

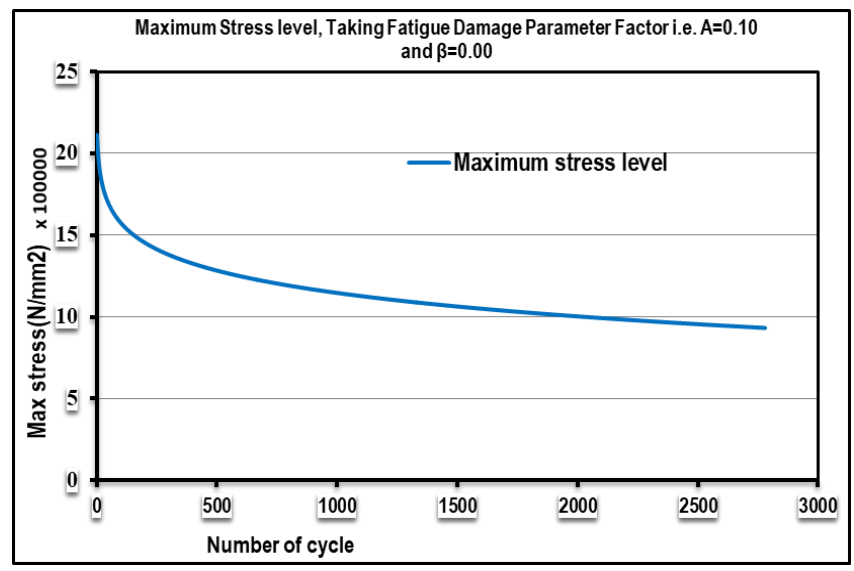

Figure 14. Model prediction of Maximum Stress Level verses Number of Cycle under uniaxial fatigue loading. Adopting the Value of Fatigue Damage Parameter, $\mathrm{A}=0.10$ and $\beta=0.00$

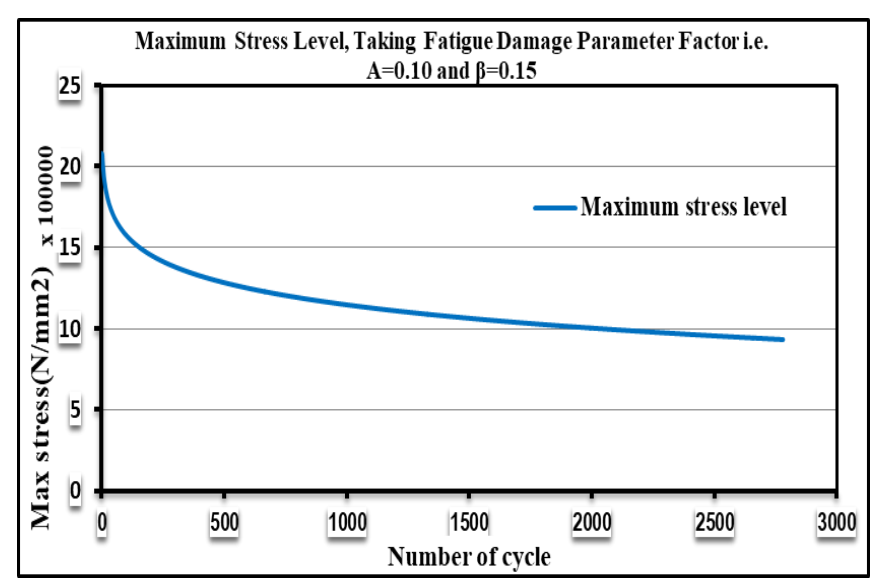

Figure 15. Model prediction of Maximum Stress Level verses Number of Cycle under uniaxial fatigue loading. Adopting the Value of Fatigue Damage Parameter, $A=0.10$ and $\beta=0.15$

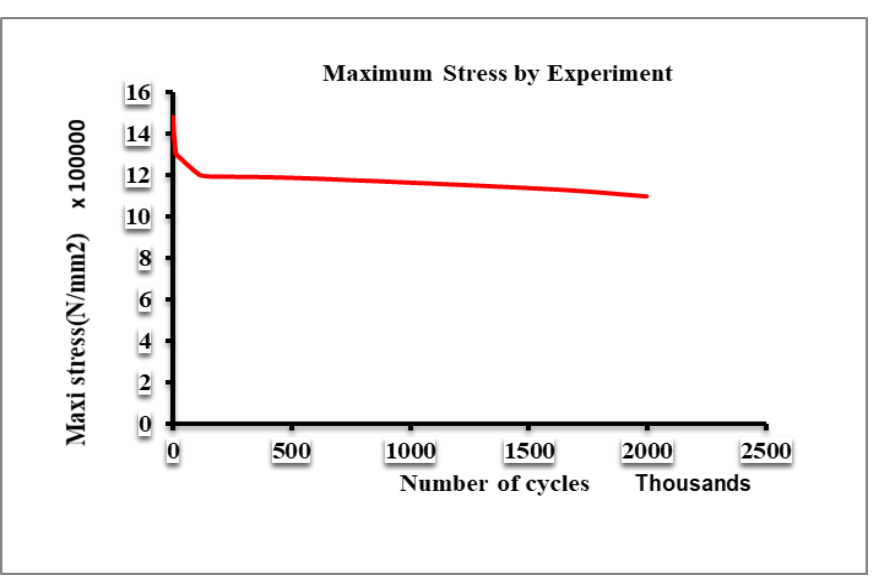

Figure 16. Reduction in maximum stress level during cyclic tension. Prediction of the theory, Figure 8 and 9 by Peivin Lu. Et. Al 2004

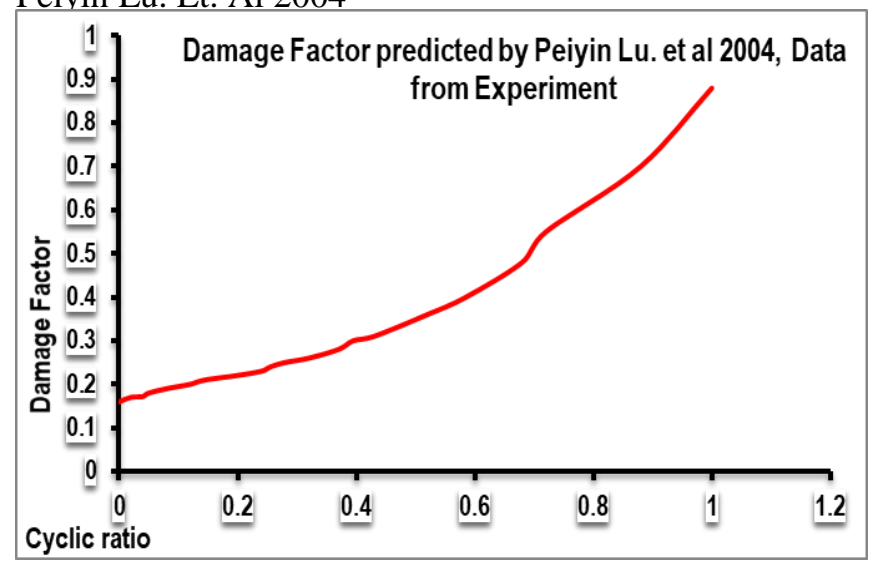

Figure 17. Variation of damage with the number of cyclic loading. Prediction of the theory, Figure (4) and Figure (5). Experimental Figure [11], by Peiyin Lu. Et. Al 2004 


\begin{tabular}{|r|r|r|r||}
\hline \multicolumn{1}{|l|l|l|}{ No. of Cycle } & \multicolumn{1}{l|}{ Factor } & \multicolumn{1}{l|}{ Max. Stress } \\
\hline $\mathbf{m a x}$ & 1479000 & 2.2 & 158.4893192 \\
\hline 0.85 & 1461600 & 2.3 & 199.5262315 \\
\hline 0.75 & 1305000 & 4.1 & 12589.25412 \\
\hline 0.74 & 1287600 & 4.4 & 25118.86432 \\
\hline 0.69 & 1200600 & 5.05 & 112201.8454 \\
\hline 0.685 & 1191900 & 5.2 & 158489.3192 \\
\hline 0.68 & 1183200 & 5.75 & 562341.3252 \\
\hline 0.65 & 1131000 & 6.2 & 1584893.192 \\
\hline 0.63 & 1096200 & 6.3 & 1995262.315 \\
\hline
\end{tabular}

Table 2. Maximum Stress Observed by Peiyin Lu. Et al 2004 through Experiment

\begin{tabular}{|c|c|c|c|}
\hline Damage & Cyclic Ratio & Damage & Cyclic Ratio \\
\hline 0.16 & $\mathbf{0}$ & $\begin{array}{l}0.25 \\
\end{array}$ & $\begin{array}{r}0.28 \\
\end{array}$ \\
\hline $\mathbf{0 . 1 7}$ & 0.02 & 0.26 & 0.32 \\
\hline 0.172 & 0.04 & 0.28 & $\mathbf{0 . 3 7}$ \\
\hline 0.18 & 0.05 & 0.3 & 0.395 \\
\hline 0.19 & 0.08 & $\mathbf{0 . 3 1}$ & 0.43 \\
\hline 0.195 & 0.1 & 0.36 & 0.52 \\
\hline 0.2 & 0.12 & 0.4 & 0.585 \\
\hline 0.21 & 0.145 & 0.48 & 0.68 \\
\hline 0.22 & 0.198 & 0.55 & 0.72 \\
\hline 0.23 & 0.24 & 0.7 & 0.88 \\
\hline 0.24 & 0.255 & 0.88 & 1 \\
\hline
\end{tabular}

Table 3. Damage predicted by Peiyin Lu. Et al 2004 through Experiment

Figures (10) and (11) show the increase in damage with increase in loading cycles. The experimental work of Figures [16] and [17] are also shown for comparison. The theoretical model also captures the similar trend of increasing damage with the cyclic loading as observed in the experiment [Figure 17]. For numerical simulation, the following constant were used, $\mathbf{A}=\mathbf{0 . 1 0}$ and $\beta=\mathbf{0 . 1 5}$ and 0.00 in two cases, Parameter $\mathrm{A}$ is estimated by comparing predicted results and experimental results over a range of applied strains from Table (2) and Table (3).

\subsection{Damage Linear Model to estimate the life of Plain Concrete in Compression, Tension and Flexure}

It is widely accepted that the Aas-Jakobsen and Lenshow's linear model can be used to estimate the fatigue life of plain concrete in tension, compression, and flexure. The model shows the relationship between the fatigue strength of concrete after a given number of cycles and the ratio of the minimum to maximum stress level. The material parameter $(\beta)$ required in the model proposed by Aas-Jakobsen and Lenshow (1970) was 0.064 . Oh (1986), proposed a material parameter of 0.069, after conducted flexural tests on plain concrete. To account for other plain lightweight concrete, Tepfers and Kutti (1979) proposed a material parameter of 0.0685.

$S_{\max }=1-\beta(1-R) \log N_{f}$

In equation (35), $\mathbf{S}_{\max }=$ ratio of the maximum stress level to the concrete compressive strength, $\mathbf{N}_{\mathbf{f}}=$ number of cycles to failure, And $\mathbf{R}=$ stress ratio [minimum stress level $\left(\boldsymbol{\sigma}_{\min }\right)$ to maximum stress level $\left.\left(\boldsymbol{\sigma}_{\max }\right)\right]$. As a means of predicting the fatigue life of steel fiber concrete using the Aas-Jakobsen's stress-life model, Singh and Kaushik (2001) developed material parameters for steel fiber concrete with fiber volume contents of $0.5 \%, 1 \%$, and $1.5 \%$ using flexural fatigue tests, obtained the values of $0.0536,0.0425$, and 0.0615 , respectively. Although the attempt seems to be reasonable, the material parameters obtained indicated a lower fatigue life as the steel fiber volume increases from $1.0 \%$ to $1.5 \%$. The proposed material parameters also exhibited higher fatigue life for steel fiber concrete with volume content of $0.5 \%$ compared with steel fiber concrete with a volume content of $1.5 \%$.

From different literature, the fatigue life of a concrete element can be predicted from its strain evolution, because a correlation was found to exist between the secondary strain rate and the number of cycles to failure. From experimental investigations reported in the literature, this approach is not significantly affected by the stochastic influence of concrete. However, the use of such models still requires the fatigue stress levels. Equation (35) can be expressed as:

$\log \left(1-S_{\max }\right)=\log \beta+\operatorname{Vog}\left(\log N_{f}\right) \ldots \ldots \ldots$

Where, $\mathrm{V}=(1-\mathrm{R}) \mathrm{k}$ and $\mathrm{k}=$ constant. From the correlation between the secondary strain rate and the number of cycles to failure 
$\log \left(\log N_{f}\right)=A+B \log \varepsilon_{\text {sec }}$

Where, $\boldsymbol{\varepsilon}_{\text {sec }}=$ secondary strain rate, and "A" and "B" are constants to be obtained from experiments. A power equations correlation (nonlinear) was initially proposed by Sparks and Menzies (1973); however, the correlation between the number of cycles resulting to fatigue failure and the secondary strain rate is expressed in a linear form Equation(36) to simplify the analysis required for deriving material parameter " $\beta$ " for plain concrete and steel fiber also.

A relationship between $\underline{\log \left(\boldsymbol{1}-S_{\max }\right)}$ the secondary strain rate $\left(\varepsilon_{\text {sec }}\right)$ can be given thus:

$\log \left(1-\mathrm{S}_{\max }\right)=\mathrm{C}+\mathrm{D} \log \varepsilon_{\text {sec }}$

"C" and "D" are constants obtained from experiments as given in Table (4).

From Eqs. (37) and (38)

$\log \varepsilon_{\text {sec }}=\frac{\log \left(\log N_{f}\right)-A}{B}$

$\log \varepsilon_{\text {sec }}=\frac{\log \left(1-S_{\max }\right)-C}{D}$

From Eqs. (39) and (40)

$\log \left(1-S_{\max }\right)=\frac{(C B)-(A D)}{B}+\frac{D}{B} \log \left(\log N_{f}\right) \ldots$

$\mathrm{T}_{0}=\frac{(C B)-(A D)}{B}$

By comparing equations (36) and (41) the material parameter required in the $\mathrm{S}-\mathrm{N}$ model can be obtained thus:

$\beta=10^{T_{0}}$

\begin{tabular}{|l|r|r|r|r|r|}
\hline \multicolumn{6}{|c|}{ Table Material Parameter for Plain and Steel Fiber Reinforcement Concrete } \\
\hline $\begin{array}{l}\text { Fibre } \\
\text { Volume } \\
\begin{array}{l}\text { Content } \\
\% \text { Vf }\end{array}\end{array}$ & Coefficient A & Coefficient B & Coefficient C & Coefficient D & $\begin{array}{l}\text { Material } \\
\text { parameter B }\end{array}$ \\
\hline 0 & -0.0996 & -0.2979 & -1.1843 & -0.0637 & 0.0687 \\
\hline 0.75 & -0.759 & -0.1559 & -1.8997 & -0.1374 & 0.0588 \\
\hline 1.5 & -0.7045 & -0.1479 & -2.0726 & -0.1564 & 0.047 \\
\hline
\end{tabular}

Table 4. Value of Coefficients and Material Parameter
- Degradation in Residual Strength and Secant Modulus

Modified damage evolution models has been proposed for concrete residual strength and fatigue secant modulus [Equation (44)] (Isojeh et al. 2017). The models are functions of the maximum stress level, critical damage value, loading frequency, damage parameter " $\mathbf{s}$ " and material parameter $\beta$. The critical damage is the percentage reduction in concrete strength or fatigue secant modulus at failure. The mathematical Model is

$D=D_{c r} \exp \left[s\left(\frac{\Delta f}{f_{c}^{\prime}}-C_{f}\right)\right] N^{v}$

$v=0.434 s C_{f}[\beta(1-R)]$

From Zhang et al. (1996), on influence of loading frequency

$C_{f}=a b^{-\log f}+C$.

Where, $\mathbf{N}=$ number of cycles; $\mathbf{s}=$ damage parameter; $\mathbf{D}_{\text {cr }}=$ critical damage value; and $\mathbf{C}_{\mathbf{f}}$ accounts for fatigue frequency.

From different investigation reports in the literatures have shown that the concrete strength and the stiffness reduce progressively after fatigue loading cycles have been applied (Cook and Chindaprasirt, 1980; Schaff and Davidson, 1997; Edalatmanesh and Newhook, 2013; Isojeh et al., 2017a). To account for this, concrete strength may be modified by using a damage factor $D_{f c}$. Similarly, the stiffness or secant modulus of concrete may be modified using a corresponding damage factor $\boldsymbol{D}_{c e}$. Models used for these cases are given thus

$D=D_{c r} \exp \left[s\left(\frac{\Delta f}{f_{c}^{v}}-u\right)\right] N^{v}$

Where,

$v=0.434 s C_{f}[\beta(1-R)]$

$C_{f}=a b^{-\log f}+C$. 
$u=C_{f}\left(1-\gamma_{2} \log \left(\zeta N_{f} \mathrm{~T}\right)\right.$

$\beta=0.0661-0.0226 R$

$\gamma_{2}=2.47 \times 10^{-2}$

$\zeta$ is a dimensionless coefficient which is taken as 0.15 for a sinusoidal cycle (Torrenti et al., 2010; Zhang et al., 1998), $C_{f}$ accounts for the loading frequency, and $\gamma_{2}$ is a constant which accounts for high stress level. From Zhang et al. (1996) on influence of loading frequency, $C_{f}=a b^{-\log f}+C$

Where, a, b and $\mathbf{c}$ are $0.249,0.920$ and 0.796 respectively, and $\mathrm{f}$ is the frequency of the fatigue loading. Depending on the value of "s" estimated from equation (47), D may be taken as $D_{f c}$ or $D_{c e}$.

$D_{c r}$ is a critical damage value taken as $\mathbf{0 . 3 5}$ for concrete strength and $\mathbf{0 . 4}$ for fatigue secant modulus (Isojeh et al., 2017a).

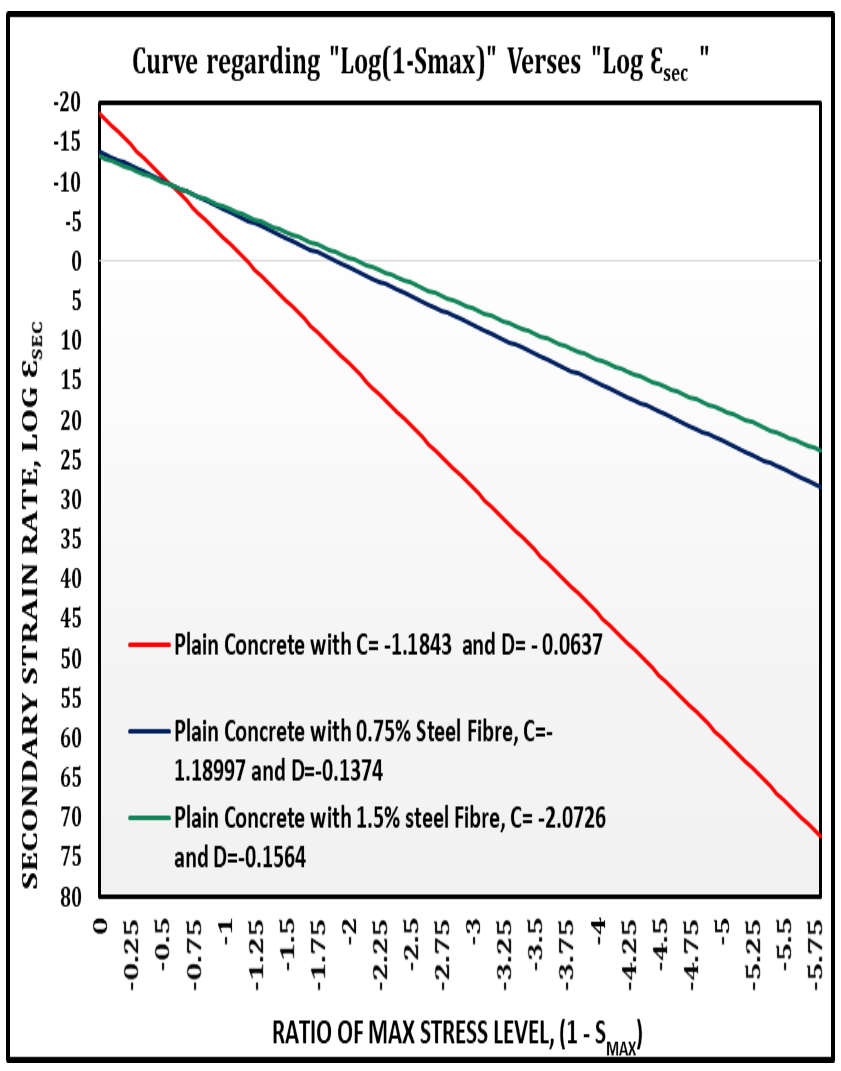

Figure 2. Secondary Strain Modeling Curve regarding " $\log \left(\mathbf{1}-\mathbf{S}_{\max }\right) "$ Verses " $\mathbf{L o g} \boldsymbol{\varepsilon}_{\mathbf{S e c}}$ " of plain concrete and plain concrete with steel fibres.

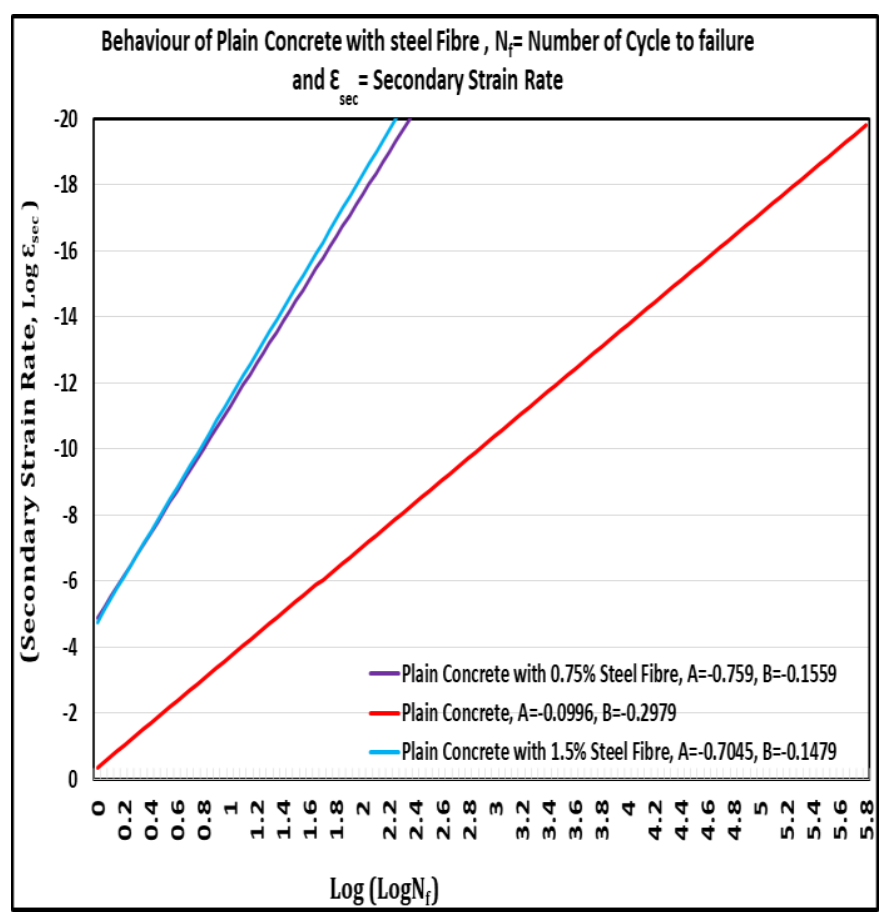

Figure 3. Behavior of Plain Concrete with steel fibre Modeling Curve regarding " $\mathbf{N}_{\mathbf{f}}$ " Verses "LogE $\boldsymbol{\varepsilon}_{\mathbf{S e c}}$ " of plain concrete and plain concrete with steel fibres.

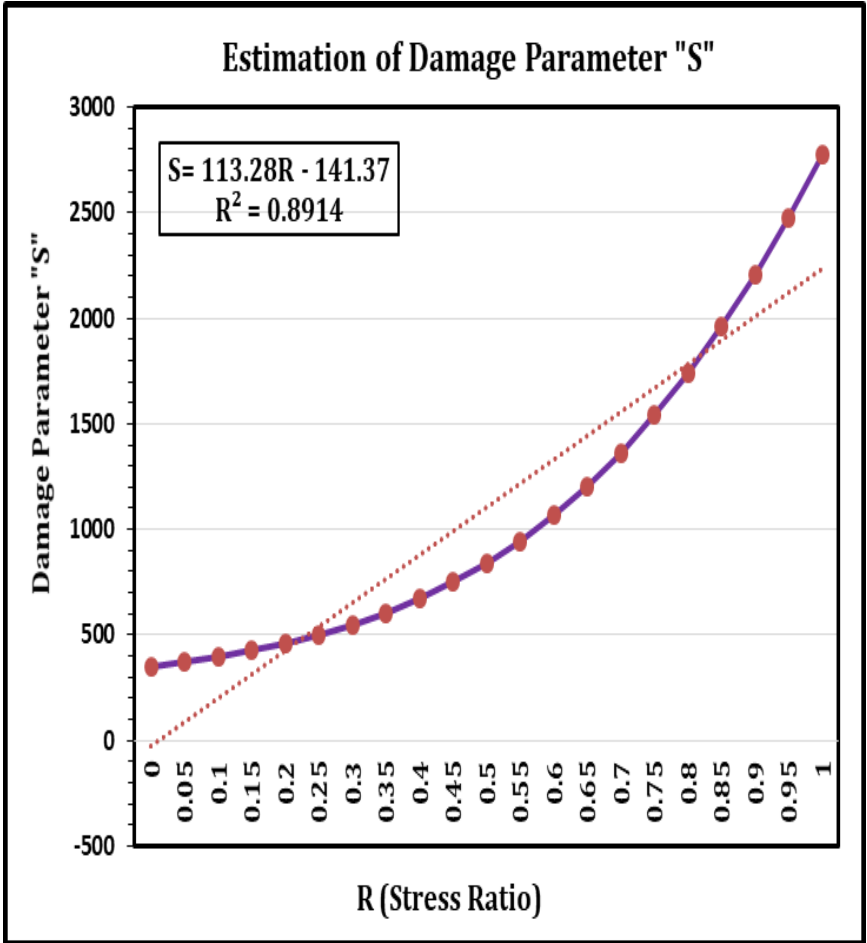


Figure 4. Estimation of Damage Parameter from Curve regarding " $\mathbf{R}$ " Verses "Damage Parameter i.e. $S$ " of plain concrete

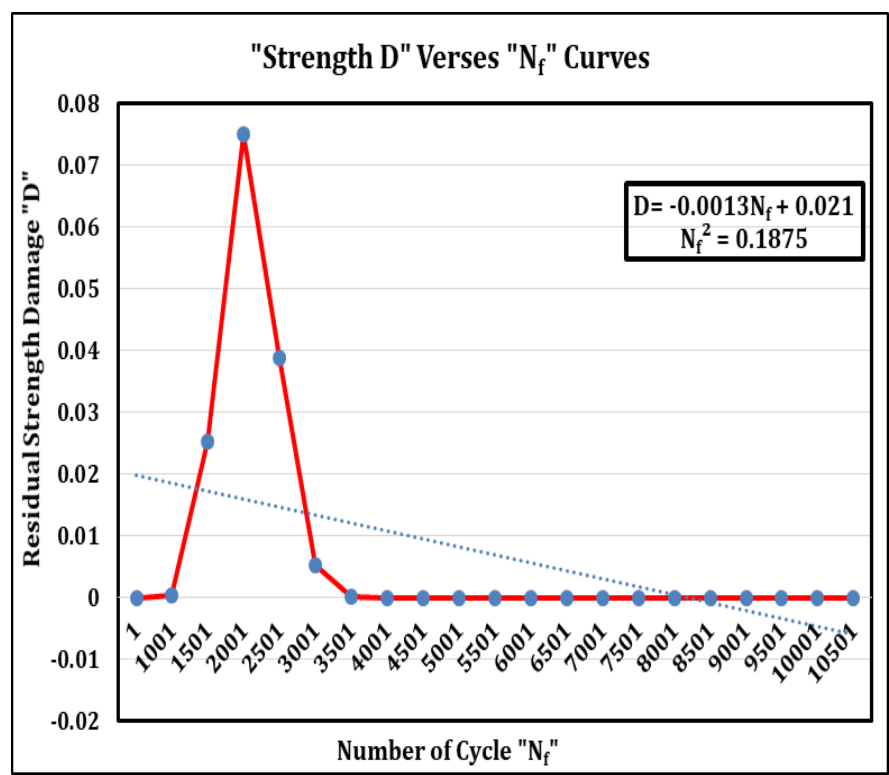

Figure 5. Estimation of Residual Strength Damage from Curve regarding " $\mathbf{N}_{\mathbf{f}}$ " Verses “ $\mathbf{D}$ " of plain concrete

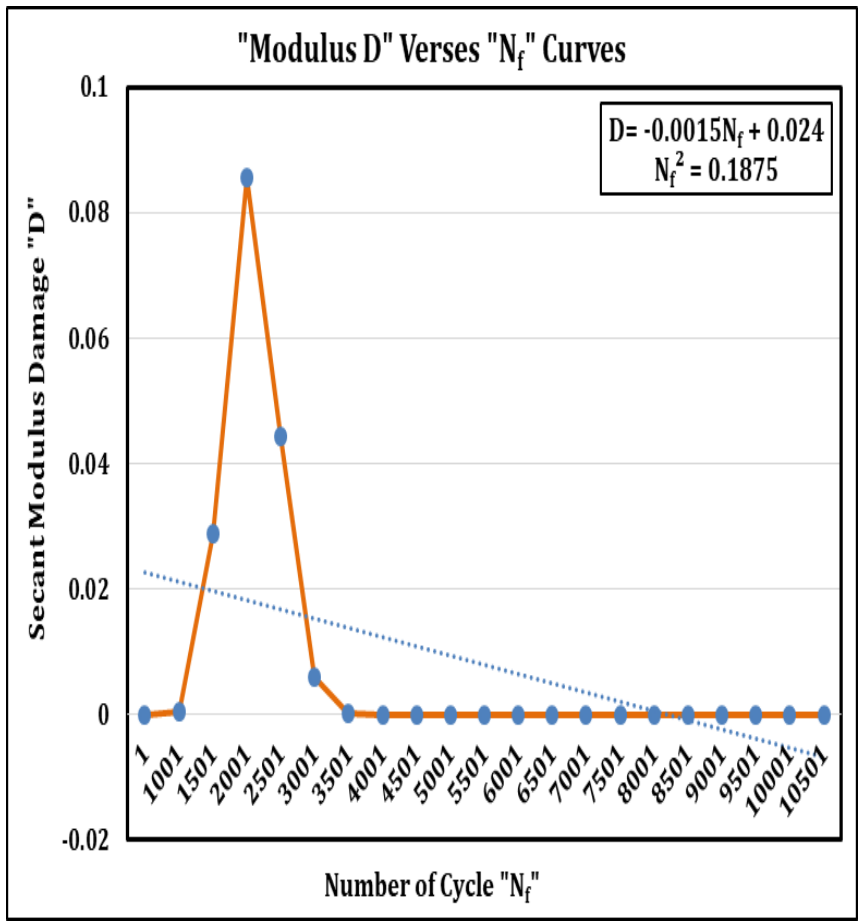

Figure 6. Estimation of Secant Modulus Damage from Curve regarding " $\mathbf{N}_{\mathbf{f}}$ " Verses "Secant Modulus Damage" of plain concrete

\subsection{Irreversible strain accumulation Model}

Compressive and tensile plastic strains accumulate in concrete under fatigue loading (Holmen, 1982; Gao and Hsu, 1998; Isojeh et al., 2017b). However, the magnitude in tension is usually small, and it is reasonable to assume it to be null. The irreversible compressive strain may be considered as a prestrain and incorporated into the strain compatibility equation. Based on an experimental investigation conducted on the strain evolution of concrete in compression (Isojeh et al., 2017b), models were proposed for the irreversible fatigue strain $(d)$ as follows:

For $0.3 N f \leq \mathrm{N} \leq N f \quad(N f$ is the number of cycles to failure and $\mathbf{N}$ is the fatigue loading cycles)

$\varepsilon_{d}=\varepsilon_{d_{0}}+\varepsilon_{d_{1}}+\varepsilon_{d_{2}}$

Where, $\boldsymbol{\varepsilon}_{d o}$ is the strain due to loops centerlines convergence, $\boldsymbol{\varepsilon}_{\boldsymbol{d} \mathbf{1}}$ is the strain due to the hysteresis loop inclination, and $\boldsymbol{\varepsilon}_{d 2}$ is the strain due to the minimum stress at the turning point of fatigue loading. The parameters equations are:

$$
\begin{aligned}
& \varepsilon_{d_{0}}=-\left(\frac{f_{c}^{I}+\left(\sigma_{\max } R\right)}{E}\right)-0.30 \varepsilon_{c}^{I} \\
& \varepsilon_{d_{1}}=\boldsymbol{k}_{2} \boldsymbol{q}\left(\frac{\boldsymbol{D}_{f c}}{\sqrt{\boldsymbol{D}_{c e}}}\right) \\
& \boldsymbol{\varepsilon}_{\boldsymbol{d}_{2}}=\frac{\boldsymbol{\sigma}_{\max } \boldsymbol{R}}{\boldsymbol{\varepsilon}_{\text {sec }}}
\end{aligned}
$$

$\mathbf{E}$ is the fatigue secant modulus, $\boldsymbol{k} \mathbf{2}$ is $\mathbf{1 . 0}$ for high strength concrete and $\mathbf{2 . 0}$ for normal strength concrete, $\mathbf{q}$ is equal to $-\mathbf{0 . 3} \boldsymbol{\varepsilon}_{c}$ ', $\mathrm{R}$ is the stress ratio, $\sigma_{\max }$ is the maximum stress level, and $E_{s e c}$ is the static secant modulus at an instance after fatigue loading. The fatigue secant modulus can be taken as $\mathbf{1 . 5} \boldsymbol{E}_{\text {sec }}$.

The first stage of deformation under fatigue loading is characterized by cyclic creep. As such, the irreversible strain for any number of cycles less than $\mathbf{3 0 \%}$ of the cycles leading to failure $\left(\boldsymbol{N}_{f}\right)$ is estimated as a function of the irreversible strain at 
0.3, where the irreversible strain at $\mathbf{0 . 3}$ is estimated using equations 1.5 to 1.8 respectively. Hence, for $\mathrm{N}<0.3 N f$,

$\varepsilon_{d}=\varepsilon_{d 3}\left(\frac{N}{0.30 N_{f}}\right)^{\delta}$

Where, $\boldsymbol{\varepsilon}_{\boldsymbol{d} \mathbf{3}}$ is the irreversible strain $\boldsymbol{\varepsilon}_{\mathbf{d}}$ value at $0.3 N_{f}$. The value of " $\delta$ " (fatigue creep constant) can be taken as $\mathbf{0 . 3}$. The implementation of the irreversible strain model into constitutive models for normal and high strength concrete are easy to describe.

However, due to limited data available for very high cycles to failure in the literature, the fatigue strain evolution tests involving very high fatigue life are also required for corroboration.

$$
N_{f}=0.0009\left(\varepsilon_{s e c}\right)^{-0.972}
$$

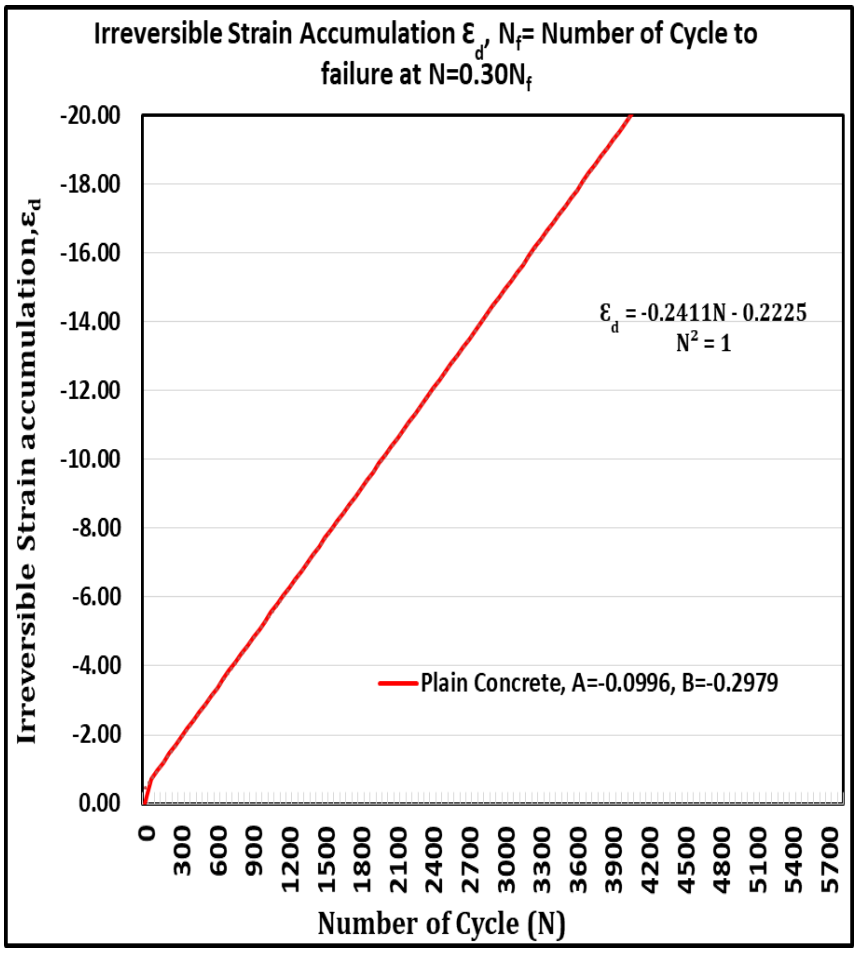

Figure 22. Irreversible Strain accumulation verses Number of fatigue cycle

\subsection{Model Validation}

\section{Experimental Study:}

Tests were conducted in order to verify the three basic assumptions used for simplifying the behaviour of concrete under fatigue loading. Monotonic tests were initially conducted on concrete cylindrical specimens in order to obtain the average compressive strength. Thereafter, percentages of the average strength were used as fatigue loads.

In the first group of fatigue tests, 22 specimens were tested at different numbers of cycles at a constant stress level and subsequently subjected to monotonic loading. The obtained stress-strain curves from monotonic loading were plotted alongside the stressstrain envelope to observe the intersection of the peak stress of the stress-strain curves with the softening portion of the stress- strain envelope. In the second group of fatigue tests, 16 specimens were tested to failure under constant fatigue loading, and the hysteresis loops were plotted. The centerline of each loop was extended in order to observe a convergence point. The intersection of the hysteresis loop at failure with the stress-strain envelope was also verified. The test procedures, the specimen tested, and the test observations are discussed subsequently.

Servo hydraulic testing equipment with a loading capacity of $1000 \mathrm{KN}$ was used to conduct fatigue tests on concrete cylinders $(100 \mathrm{~mm}$ diameter x $200 \mathrm{~mm}$ height). In all tests, the waveform of the applied fatigue loading was sinusoidal in nature. In order to measure the progressive average strains throughout the tests, LVDTs were mounted on opposite sides of each specimen

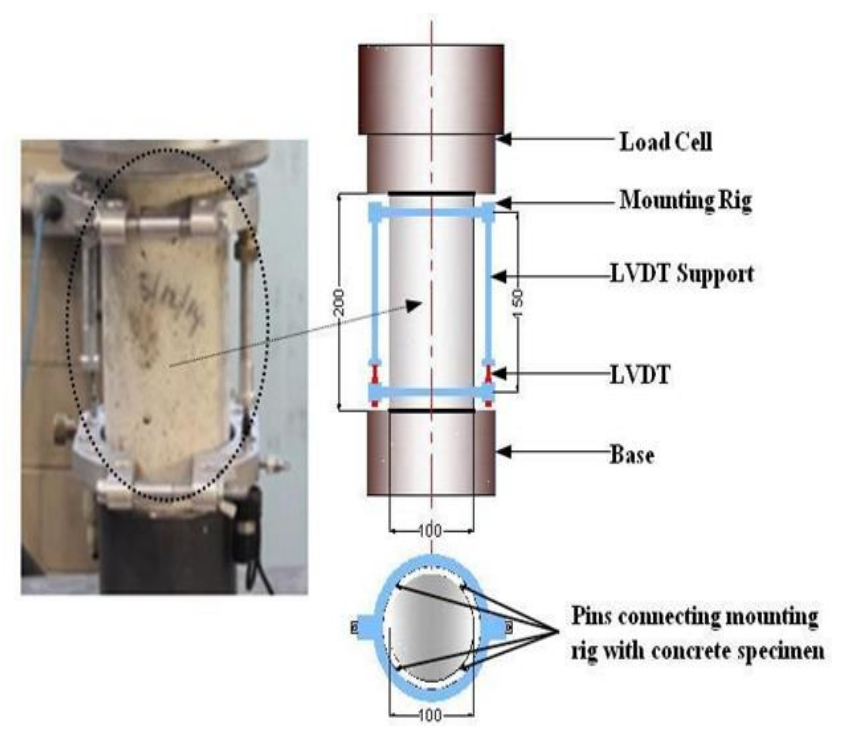




\section{Figure 23: Fatigue loading set-up Preparation of Test Specimen:}

The concrete specimens were made from Portland cement, sand, and limestone aggregates $(10 \mathrm{~mm}$ maximum size) with three different mix ratios. The concrete from the first two batches (Table 5) were cast using a mix proportion of 1: $2: 2$ with a water/cement ratio of 0.5 , indicating cement, sand, and coarse aggregate by weight respectively. Mix proportion ratios of 1:2:3 with a water/cement ratio of 0.5 and 1:2:4 with a water/cement ratio of 0.6 were used for the third and fourth batches respectively. The static strengths of concrete after curing for 28 days were obtained for each batch (Table 5), while the fatigue tests were conducted 30 to 40 days after casting.

Table 5 - Average Compressive Strength and Corresponding Strain.

\begin{tabular}{|l|l|l|l|}
\hline $\begin{array}{l}\text { Specimen } \\
\text { Sample } \\
\text { No. }\end{array}$ & $\begin{array}{l}\text { Average } \\
\text { Compressive } \\
\text { Strength }(\mathrm{MPa})\end{array}$ & $\begin{array}{l}\text { Average } \\
\text { Corresponding } \\
\text { Strain }(\mathrm{x} 0.001)\end{array}$ & \\
\hline 1 & 52.8 & 2.01 & $1: 02: 02$ \\
\hline 2 & 55.8 & 2 & $1: 02: 02$ \\
\hline 3 & 46.2 & 1.95 & $1: 02: 03$ \\
\hline 4 & 23.1 & 1.52 & 1.2 .4 \\
\hline
\end{tabular}

Percentages of the average compressive strengths of the four batches $(69 \%$ to $80 \%)$ were used as maximum stress levels for the fatigue tests conducted on 16 specimens to failure (Table 6). The 22 specimens loaded to different numbers of cycles less than the number of cycles leading to failure at a constant maximum stress level of 0.74 (Table 6) and a frequency of $5 \mathrm{~Hz}$ are given in Table 6. A constant minimum load of $5 \mathrm{kN}$ was used for all the tests conducted. The approach for estimating the fatigue secant modulus will be discussed in a subsequent section.

Table 6 - Percentage of Average Compressive Strength for Fatigue Loading

\begin{tabular}{|l|l|l|l||}
\hline $\begin{array}{l}\text { Specimen } \\
\text { Sample } \\
\text { No. }\end{array}$ & $\begin{array}{l}\% \text { of Average } \\
\text { Comp. Strength } \\
(\mathrm{Mpa})\end{array}$ & $\begin{array}{l}\text { Average } \\
\text { Compressive } \\
\text { Strength (Mpa) }\end{array}$ & $\begin{array}{l}\text { Freq. } \\
(\mathrm{Hz})\end{array}$ \\
\hline 1 & 74 & 52.8 & 5 \\
\hline 1 & 69 & 52.8 & 5 \\
\hline 2 & 80 & 55.8 & 5 \\
\hline 3 & 74 & 46.2 & 5 \\
\hline 4 & 75 & 23.1 & 5 \\
\hline 4 & 75 & 23.1 & 1 \\
\hline \hline
\end{tabular}

The progressive strain readings of the concrete cylinders (100 mm diameter x $200 \mathrm{~mm}$ height) tested under uniaxial constant fatigue loading in compression were obtained using a data acquisition system. The specimens tested to failure were used to verify Park's (1990) assumption and that of the intersection of the hysteresis loop with the stressstrain envelope at failure. The 22 specimens tested to different numbers of cycles before failure were used to verify the assumption of the intersection of the peak stress with the softening portions of the stressstrain envelope.

The servo hydraulic testing equipment used was unable to properly capture the softening of concrete after attaining peak strength due to the insufficient stiffness of the MTS (Material Testing Systems) setup used; hence, the average compressive strength and the corresponding average peak strain values obtained from monotonic tests were substituted into Popovics' (1973) and Hognestad's (1954) stress-strain equations for high and normal strength concrete, respectively. The stress-strain curves generated were used as the stress-strain envelopes required to verify the intersection of the peak stresses for the statically loaded fatigue-damaged specimens. However, the stress-strain curves obtained from the experiments were alsoincluded in the plots.

\section{Failure Modes:}

Figure 24 shows specimens in various damaged states. The hairline cracks parallel to the applied loading direction were initially observed in the entire specimen. Thereafter, the cracks widened and finally failed in the form of faults. 
Figure 24: Specimens in damaged states

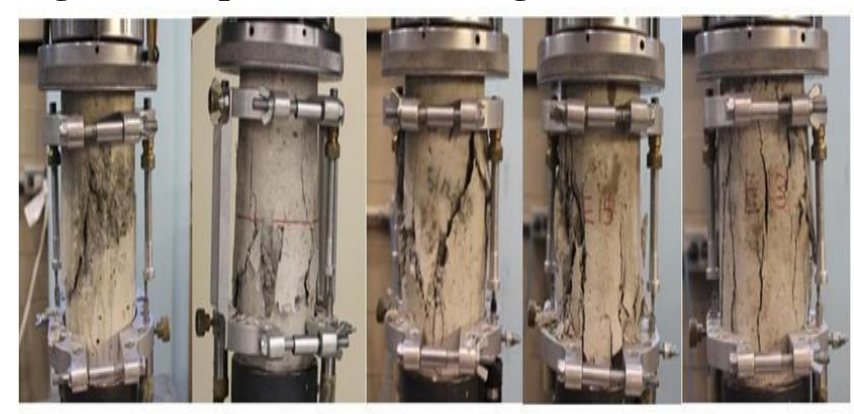

Experimental Results and Verification

Table 7. Experimental Results

\begin{tabular}{|c|c|c|c|c|c|}
\hline Specimen & $\begin{array}{c}\text { Initial } \\
\text { Compressive } \\
\text { Strength }\end{array}$ & $\begin{array}{c}\text { Number of } \\
\text { Cycles before } \\
\text { static loading }\end{array}$ & $\begin{array}{c}\text { Residual } \\
\text { strength after } \\
\text { loading }\end{array}$ & $\begin{array}{c}\text { Residual } \\
\text { fatigue } \\
\text { Modulus }\end{array}$ & $\begin{array}{c}\text { Corresponding } \\
\text { static secant } \\
\text { Modulus }\end{array}$ \\
\hline & & & Mpa) & (Mpa) & (Mpa) \\
\hline S1 & 52.8 & 430 & 54.9 & 68900 & 41900 \\
\hline S2 & 52.8 & 430 & 54.4 & 58100 & 38500 \\
\hline S3 & 52.8 & 860 & 55.1 & 65100 & 40200 \\
\hline S4 & 52.8 & 860 & 53 & 58800 & 37100 \\
\hline S5 & 52.8 & 5150 & 55.3 & 62000 & 39000 \\
\hline S6 & 52.8 & 7730 & 52.3 & 55200 & 35000 \\
\hline S7 & 52.8 & 8160 & 53.4 & 53300 & 35500 \\
\hline S8 & 52.8 & 3480 & 46.5 & 44200 & 30500 \\
\hline S9 & 46.2 & 5550 & 41.7 & 33400 & 23500 \\
\hline S10 & 46.2 & 5880 & 38.6 & 30100 & 21600 \\
\hline S11 & 46.2 & 18100 & 36.3 & 31400 & 21900 \\
\hline S12 & 46.2 & 6180 & 32.9 & 25800 & 17600 \\
\hline S13 & 55.8 & 5000 & 51.4 & 50200 & 31800 \\
\hline S14 & 55.8 & 1200 & 58.1 & 61800 & 39700 \\
\hline S15 & 55.8 & 3000 & 56.2 & 57600 & 36800 \\
\hline S16 & 55.8 & 6120 & 45.6 & 45100 & 29200 \\
\hline S17 & 55.8 & 5840 & 49.2 & 43900 & 28800 \\
\hline S18 & 55.8 & 7900 & 44.7 & 42800 & 28300 \\
\hline S19 & 55.8 & 4680 & 36.1 & 37200 & a \\
\hline S20 & 55.8 & 6710 & 52.5 & 54300 & 34600 \\
\hline S21 & 55.8 & 9870 & 46.8 & 38800 & 26700 \\
\hline S22 & 55.8 & 8660 & 37.9 & 33300 & a \\
\hline a Failed before reaching maximum fatigue load applied & \\
\hline
\end{tabular}

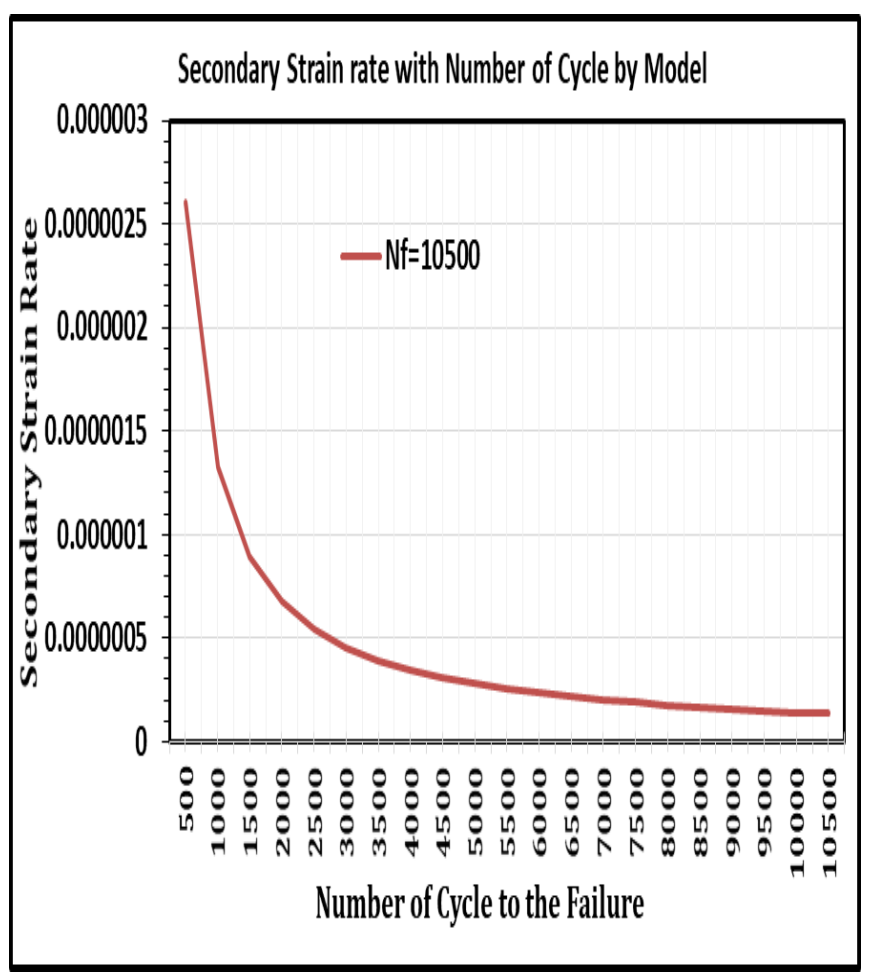

Figure 25. Secondary Strain Rate by Number of Cycle to failure by Model

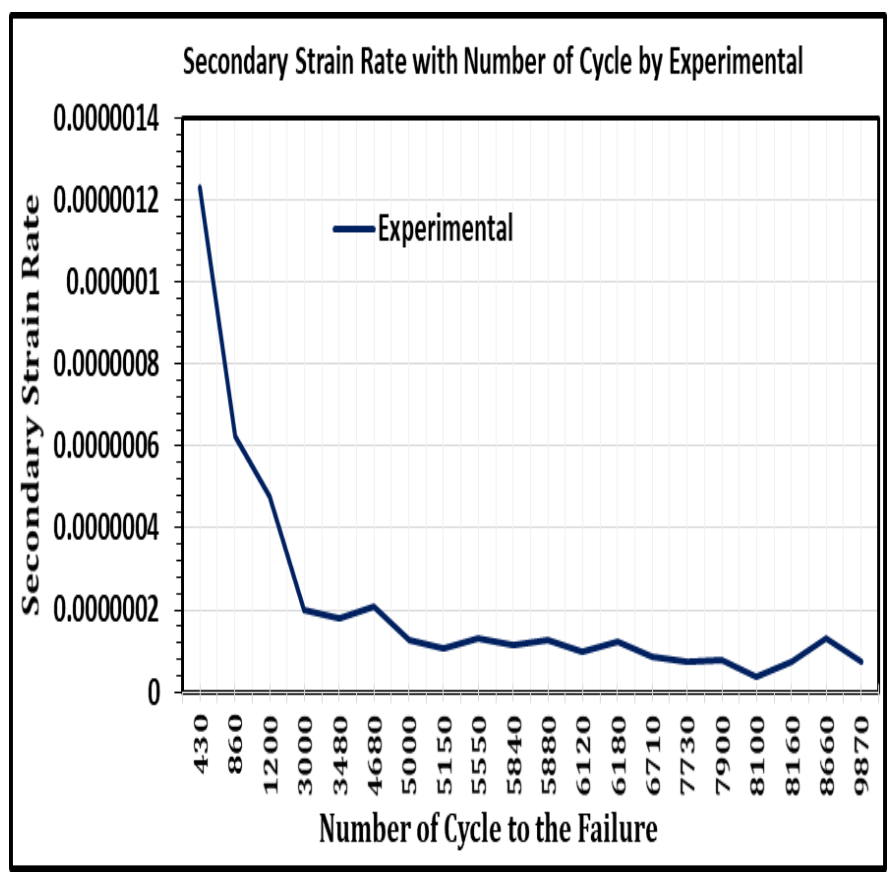

Figure 265. Secondary Strain Rate by Number of Cycle to failure by Model 


\subsection{Conclusions}

\subsection{Fatigue Damage Model by utilizing} continuum thermodynamics Approach:

Strain Based Model of Concreet Material during low frequency is presented in this paper by utilizing the framework of continuum thermodynamics of Continuum Mechanics by taking two material fatigue damage parameter i.e. mathematical symbol, $A$ and $\beta$ (where, $\mathrm{A}=$ fatigue damage Parameter regarding energy microcracks of the material particle and another is $\beta=$ kinematic damage Parameter i.e. phenomena of material crack surface close perfectly after unloading). Fatigue damage evolution law together with the damage response functions were used in the constitutive relation to demonstrate the capability of the model in capturing the essential features of concrete material, such as stiffness reductions, increase in damage parameters, behaviour of fatigue modulus and the inelastic deformations, under fatigue loading environment by finding out the cumulative fatigue damage parameter i.e. symbolically, $\mathrm{K}$. The fatigue curve relavant to $\mathrm{A}=$ 0.10 and $\beta=0.15$ and 0.00 is generated by the modeling and after that this generated model curve is compared to the curve obtained by Peiyin Lu. Et al (2004) which shows similar tread of generation of fatigue curve. This also shows the good relation between results obtained from modeling and experiments. Lower value in the experimental curve is due to 0.85 times maximum stress level whereas, modeling takes $100 \%$ value.

\subsection{Concrete Fatigue Strain Evolution Analysis.}

(1) By analyzing the short comings and limitations of existing fatigue strain evolution equations, the level-S nonlinear evolution model of fatigue strain, which contains the initial strain, was constructed. Then, the physical meaning of the parameters and the range and the impact on the shape of the curve were all discussed. (2) The results show that the level-S model covered all types of fatigue strain evolution and has strong adaptability and high accuracy. The model could be tested for applicability to steel fiber reinforced concrete, glass fiber reinforced concrete, and a variety of characteristics of concrete. (3)The fatigue modulus evolution model was established under constant amplitude bending fatigue loading based on fatigue strain evolution model and the hypothesis of fatigue modulus inversely related to fatigue strain amplitude. (4) The evolution curve of the fatigue strain and the fatigue modulus both have three stages of variation, and the middle stage is nearly linear. When the recycle ratio is 0.9 , two curves converge quickly representing the difference of the fatigue strain evolution curve from the lower left corner to the upper right corner, but the fatigue modulus evolution curve is from the upper left corner to the right lower corner.

9.30 Concrete Fatigue Modulus Evolution Analysis. The fitting results of the maximum fatigue strain and fatigue residual strain under different stress levels using the model equations (21) to (22) are shown in Figures. Coefficients of the evolutionary model are shown in Table (???). The data in the figures are the average of each group i.e group A, B, C. From Figures and Tables of evolutionary Model, fatigue strain evolution equations (4) and (5) (make it consistency when you express equations numbers, figures and tables; follow the exact format. Here you mentioned somewhere bold letters, somewhere normal fonts and somewhere you wrote "Eqn." and somewhere "equation". Follow the exact pattern) can be a good correlation with the experimental dataabove $\mathbf{0 . 9 8}$ of correlation of coefficients. The evolution of the maximum fatigue strain and the fatigue residual strain have similar three-phase variation and the intermediate stage close to the linear change. The curve converged rapidly when the cycle ratio exceeded approximately 0.9 . The strain evolution curve is the level-S-shaped curve from the lower left corner to the upper right corner. Because the experiment measured only the initial maximum strain and has not measured initial residual strain, the evolution curve of the maximum strain starts from the initial value, but the evolution curve of fatigue residual strain starts from zero.

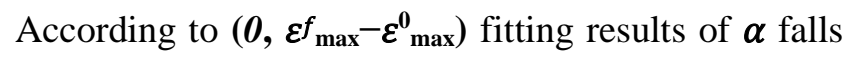
in these ranges, in line with the boundary conditions.The Fatigue Strain Parameter, changes in 
elastic modulii is established inversely with the fatigue strain.

\subsection{Fatigue Damage evolution Model}

Damage parameter at any number of fatigue loading to number of cycle at failure is well establiseh by adopting (i) $\varepsilon_{\text {max }}^{0} / \varepsilon_{\text {max }}^{\mathrm{f}}=0.60, p=2.00, \propto / \varepsilon_{\text {max }}^{\mathrm{f}}=0.10$, $\beta=1.05$ (ii) $\varepsilon_{\text {max }}^{0} / \varepsilon_{\text {max }}^{\mathrm{f}}=0.60, p=2.00, \alpha / \varepsilon_{\text {max }}^{\mathrm{f}}=0.15$, $\beta=1.140625 \quad$ (iii) $\varepsilon_{\text {max }}^{0} / \varepsilon_{\text {max }}^{\mathrm{f}} \quad=0.60, \quad p=2.00$, $\propto / \varepsilon_{\text {max }}^{\mathrm{f}}=0.20, \beta=1.25$ (iv) $\varepsilon^{0}{ }_{\text {max }} / \varepsilon^{\mathrm{f}}$ max $=0.60, p=2.00$, $\propto / \varepsilon_{\text {max }}^{\mathrm{f}}=0.25, \quad \beta=1.390625 \quad(\mathrm{v}) \varepsilon^{0}{ }_{\text {max }} / \varepsilon^{\mathrm{f}}$ max $\quad=0.60$, $p=2.00, \propto / \varepsilon_{\text {max }}^{\mathrm{f}}=0.30, \beta=1.5625$.

\subsection{Fatigue Damage linear model in} compression, tension and flexute of concrete

Estimation of fatigue life of concrete in compression, tension and flexure are well established by finding out the relative values of $\mathbf{S}_{\mathbf{m a x}}, \boldsymbol{\varepsilon}_{\mathbf{s e c}}$, their affecting parameters such as a, b, c, A, B, C, D, degradation in secant strength, elastic modulli and secant modulus.

\subsection{Fatigue Irreversible Strain accumulation Model}

$\boldsymbol{\varepsilon}_{d o}, \boldsymbol{\varepsilon}_{d 1} \boldsymbol{\varepsilon}_{d 2}, \boldsymbol{\varepsilon}_{d}$ is established by modeling. Relation of secondary strain regarding $0.3 N f \leq \mathrm{N} \leq N f$ ( $N f$ is the number of cycles to failure and $N$ is the fatigue loading cycles) is established. Corroboration of model is established from equation, $N_{f}=\mathbf{0 . 0 0 0 9}$ $\left(\varepsilon_{s e c}\right)^{-0.972}$

\subsection{Authors' contributions}

All authors read and approved the final manuscript.

\subsection{Author details}

${ }^{1}$ Assistant Professor, Ph.D. Research Scholar, Department of Civil Engineering, Pulchowk Campus, Institute of Engineering, Tribhuvan University, Nepal,

2 Associate Professor, Department of Civil Engineering, Pulchowk Campus, Institute of Engineering, Tribhuvan University, Nepal Corresponding emails: eecconsultant@gmail.com, ${ }^{2}$ kamal.thapa@ioe.edu.np

\subsection{Acknowledgments}

The authors express their gratitude to the Dean Office, Institute of Engineering, Departiment of Civil Engineering, Pulchowk CampusTribhuvan University CARD Section and NTNU Norway for their invaluable contributions and financial support as sholarship to this research. The authors also acknowledge the assistance received from NTNU, Norway through CARD Section of IOE, Pulchowk Campus, Tribhuvan University.

\subsection{Competing interests}

The authors declare that they have no competing interests.

\subsection{Availability of data and materials}

Not applicable.

\subsection{Consent for publication}

Not applicable.

\subsection{Ethics approval and consent to participate}

Not applicable.

\subsection{Funding}

Not applicable.

\subsection{References}

[1] European Union - BriteEURamIII (2000) Fatigue of Normal Weight Concrete and Lightweight Concrete, Document BE 96-3942/R34.

[2] Szerszen, M.M. (2013) Fatigue damage model for ordinary concrete. Open journal of Functional Material Research (OJFMR), 1(2), 17-20

[3]Rao, S. and Roesler, J. (2004) Cumulative Fatigue Damage Analysis of Concrete Pavement using Accelerated Pavement Testing Results. In: Proceedings of the 2nd International Conference on Accelerated Pavement Testing, Minneapolis, Sep.

[4]Dyduch, K., Szerszen, M.M. and Destrebecq, J-F (1994) Experimental Investigation of the Fatigue Strength of Plain Concrete under High Compressive Loading. Structures and Materials, 27 (173), 505-509.

[5] L $\mathrm{u}^{\ddot{u}}$ p., Li, Q., Song, Y. (2004) Damage Constitutive of Concrete under Uniaxial Alternate 
Tension-Compression Fatigue Loading Based on Double Bounding Surfaces. International Journal of Solids and Structures, 41, 3152-3166.

[6]Fardis, M.N., Alibi, B. and Tassoulas, J.L. (1983) Monotonic and Cyclic Constitutive Law for Concrete. J. Engrg, ASCE, 108EM2, 516-536.

[7]Yang, B.L., Dafalias, Y.F., Herrmann, L.R. (1985) A Bounding Surface Plasticity Model for Concrete, Proc. Paper 19539. J. Engg. Mech., ASCE 111/EM3, 359-380.

[8] Sauris, W., Ouyang, C., Fernando, V.M. (1990) Damage Model for Cyclic Loading for Concrete. J. Engg. Mech., ASCE 116(5), 1020-1035.

[9] Papa, E. (1993) A Damage Model for Concrete Subjected to Fatigue Loading. Eur.J. Mech. A/solids, 12(3), 449-440.

[10] Khan, K.R., Al-Gadhib, A.H., Baluch, M.H (1998) An Elasto-Damage Constitutive Model for High Strength Concrete. In: Proceeding of the EURO-C 1998 Conference on computational model of concrete structure at Austria, March, 133-142

[11] Thapa, K.B., Yazdani, S. (2013) Combined Damage and Plasticity Approach for Modeling Brittle Materials with Application to Concrete. International Journal of Civil and Structural Engineering, 3(3), 513-525.

[12] Choboche, J.L. (1992) Damage Induced Anisotropy: On the Difficulties Associated with the Active/Passive Unilateral Conditions. Int. J. Damage Mechanics, 1, 148-171.

[13] Coleman, B.D. \& Girtin, M.E. (1967), Thermodynamics with International State Variables. J. Chem. Phys., 47(2), 597-613.

[14] Smith, G.M. \& Young, L.E. (1955) Ultimate Theory in Flexure by Exponential Function. Proceedings of the American Concrete Institute, 52(3), 349-359.

[15] Thapa, K.B., Yazdani, S. (2014) A Strain Based Damage Mechanics Model for Plain Concrete. International Journal of Civil Engineering Research, 5(1), 27-40.

[16] Duggal, S.K. (2009). "Building materials". New Delhi, India. New Age International
[17] Edward, S. H. and David P. G., (2009). "Concrete construction". Edward S. Hoffman, Ltd., Chicago.

[18] Gambhir, M .L. (2005) "Concrete technology", Third edition Tata McGraw- Hill Publishing Company Limited, New Delhi.

[19] Neville A. M., (2011). "Properties of concrete". Fifth edition. Pearson Publications, Harlow, England. UK.

[20] Shetty M. S., (2005). "Concrete technology: Theory and practice". S. Chand \& Company, Ram

[21] Isojeh, B., El-Zeghayar, M., and Vecchio, F.J. (2017a). "Concrete Damage under Fatigue Loading in Uniaxial Compression." ACI Materials Journal, Vol. 114, No. 2, pp. 225-235.

[22] Isojeh, B., El-Zeghayar, M., and Vecchio, F.J. (2017b). "Simplified Constitutive Model for Fatigue Behaviour of Concrete in Compression." Journal of Materials in Civil Engineering, DOI: 10.1061/(ASCE)MT.1943-5533.0001863.

[23] Gao L., and Hsu C.T.T. (1998). "Fatigue of Concrete under Uniaxial Compression Cyclic Loading.” ACI Materials Journal, Vol. 95, No. 5, pp. 575-581.

[24] Herwig A. (2008). "Reinforced Concrete Bridges under Increased Railway Traffic Loads- Fatigue Behaviour and Safety Measures." Ph. D Thesis No. 4010, Ecole Polytechnique Federale de Lausanne.

[25] Holmen J.O. (1982). "Fatigue of Concrete by Constant and Variable Amplitude Loading." ACI SP Vol. 75, No. 4, pp. 71-110.

[26] Isojeh, B., El-Zeghayar, M., and Vecchio, F.J. (2017c). "Fatigue Behaviour of Steel Fiber Concrete in Direct Tension." Journal of Materials in Civil Engineering, DOI: 10.1061/ (ASCE) MT.1943-5533.0001949.

[27] Isojeh B., El-Zeghayar M., Vecchio, F.J. "Fatigue Resistance of Steel-Fiber Reinforced Concrete Deep Beams.” ACI Structural Journal, Vol. 114, No. 5, pp. 1215-1226.

[28] Isojeh B., El-Zeghayar M., Vecchio, F.J. (2017e). "High-Cycle Fatigue Life Prediction of Reinforced Concrete Deep Beams.” Engineering Structures Journal, Vol. 150, pp. 12-24. 
[29] Isojeh, M.B., and Vecchio, F.J (2016). "Parametric Damage of Concrete under HighCycle Fatigue Loading in Compression." Proc., 9th International Conference on Fracture mechanics of Concrete and Concrete Structures. FraMCoS-9 2016; 10.21012/FC9.009.

[30] Aas-Jacobsen, K. (1970). "Fatigue of concrete beams and columns." Bulletin No 70-1, Institute for Betonkonstruksjoner, Trondheim, Norway, 148.

[31] Chang, D., and Chai, W. (1995). "Flexural fracture and fatigue behaviour of steel-fiber reinforced concrete structures." Nucl. Eng. Des. 156(1-2), 201-207.

[32] Chenkui, H., and Guofan, Z. (1995). "Properties of steel fiber reinforced concrete containing larger coarse aggregate." Cem. Concr. Compos. 17(3), 199-206.

[36] A. Alliche, "Damage model for fatigue loading of concrete," International Journal of Fatigue, vol.26, no. 9, pp. 915-921, 2004

[37] Y.-C .Kuangand J.-P.Ou, "Passive smart selfrepairing concrete beams by using shape memory alloy wires and fibers containing adhesives," Journal of Central South University of Technology, vol.15, no.3, pp.411-417, 2008.

[38] J.-K. Kim and Y.-Y. Kim, "Experimental study of the fatigue behavior of high strength concrete," Cement and Concrete Research, vol.26, no.10, pp.1513-1523, 1996

[39] X. W. Luo, Test Research of the Mechanics Characteristic of Recycled Aggregate Concrete under Recurrent Load, Wuhan University of Technology, School of Civil Engineering and Architecture, Wuhan,China,2006.

[40] Y.-B. Chen, Z.-A. Lu, and D. Huang, "Fatigue defect of layer steel fiber reinforced concrete," Journal Wuhan University of Technology, Materials Science Edition, vol. 18, no. 1, pp. 65-68, 2003. [8] P. B. Cachim, J. A. Figueiras, and P. A. A. Pereira, "Fatigue behavior of fiber-reinforced concrete in compression,"
[33] Cornelissen, H. A. W., and Reinhardt, H. W. (1984). "Uniaxial tensile fatigue failure of concrete under constant-amplitude and programme loading." Mag. Concr. Res., 36(129), 216-226.

[34] C. Y. Li and Y. P. Song, "Study of residual strain of concrete under fatigue loading, "Journal of Dalian University of Technology,vol.41,no.3,pp.355-358,2001.

[35] M. K. Lee and B. I. G. Barr, "An overview of the fatigue behaviour of plain and fiber reinforced concrete," Cement \& Concrete Composites, vol. 26, no. 4, pp. 299-305, 2004. 
Cement ConcreteComposites,vol.24,no.2, pp.

211-217,2002. 